\title{
Adolescent Residential Mobility: Behavioral Outcomes and the Moderating Role of the Mother-Adolescent Relationship
}

\author{
Sloane B. Glover \\ West Virginia University, sbglover@mix.wvu.edu
}

Follow this and additional works at: https://researchrepository.wvu.edu/etd

Part of the Developmental Psychology Commons

\section{Recommended Citation}

Glover, Sloane B., "Adolescent Residential Mobility: Behavioral Outcomes and the Moderating Role of the Mother-Adolescent Relationship" (2019). Graduate Theses, Dissertations, and Problem Reports. 3879. https://researchrepository.wvu.edu/etd/3879

This Thesis is protected by copyright and/or related rights. It has been brought to you by the The Research Repository @ WVU with permission from the rights-holder(s). You are free to use this Thesis in any way that is permitted by the copyright and related rights legislation that applies to your use. For other uses you must obtain permission from the rights-holder(s) directly, unless additional rights are indicated by a Creative Commons license in the record and/ or on the work itself. This Thesis has been accepted for inclusion in WVU Graduate Theses, Dissertations, and Problem Reports collection by an authorized administrator of The Research Repository @ WVU. For more information, please contact researchrepository@mail.wvu.edu. 
Adolescent Residential Mobility: Behavioral Outcomes and the Moderating Role of the Mother-Adolescent Relationship

Sloane B. Glover, B.S.

Thesis submitted to the

College of Education and Human Services

At West Virginia University

In partial fulfillment of the requirement for the degree of

Master of Arts in Educational Psychology-

Child Development and Family Studies

Sara Anderson, Ph.D, Chair

Amy Root, Ph.D.

Jessica Troilo, Ph.D.

Department of Learning Science and Human Development

\section{Morgantown, West Virginia \\ 2019}

Keywords: Residential mobility, adolescence, externalizing, parent-adolescent relationship Copyright 2019 Sloane B. Glover 


\begin{abstract}
Adolescent Residential Mobility: Behavioral Outcomes and the Moderating Role of the MotherAdolescent Relationship
\end{abstract}

Sloane B. Glover

Prior research has noted unfavorable associations between residential mobility (RM) and youth outcomes. However, little work has considered the mother-adolescent relationship as a moderator of the suggested associations. The purpose of the current study was to examine the internalizing, externalizing, and delinquent behaviors of adolescents $\left(M_{a g e}=15.6, S D=0.77\right)$ following a move in comparison to adolescents who did not move. Frequency of moves was considered and adolescents were identified as either stable (0 moves), low mobility (1-2 moves), or high mobility ( $>2$ moves) within a 6 year period. Mother-adolescent closeness and parental monitoring were examined as potential moderators of the relationship between RM and adolescent outcomes. The researchers expected mobility status would be positively associated with internalizing, externalizing, and delinquent behaviors and aspects of the mother-adolescent relationship would influence outcomes. Results suggest adolescents who experience high RM display more externalizing and delinquent behaviors following a move when compared to stable adolescents. No associations were found between adolescents' internalizing behaviors and mobility status. Closeness between the mother and adolescent moderated the association between mobility status and externalizing behaviors, suggesting closer mother-adolescent relationships inhibited changes in externalizing behavior following a move. Implications for programs and school communities are included. 


\section{Acknowledgements}

I would like to thank my committee: Sara Anderson, Amy Root, and Jessica Troilio for their support with not only my academics, but also life's challenges over the past two years. 
Table of Contents

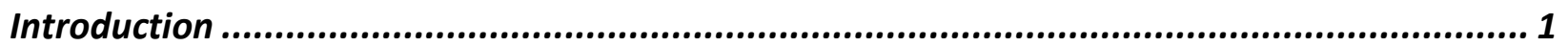

Theoretical Approach ................................................................................... 2

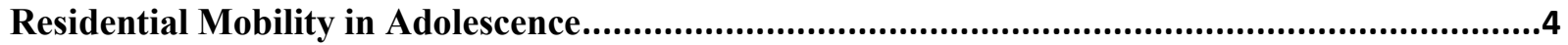

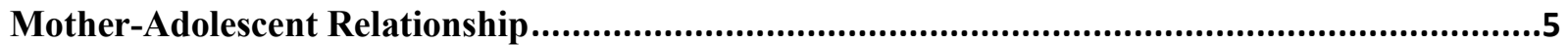

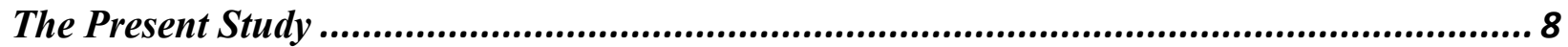

Method......................................................................................................... 10

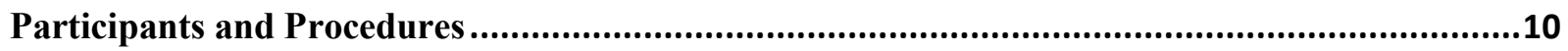

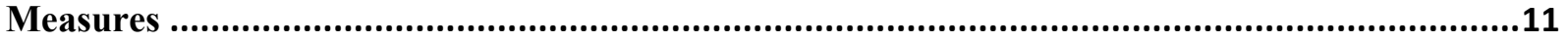

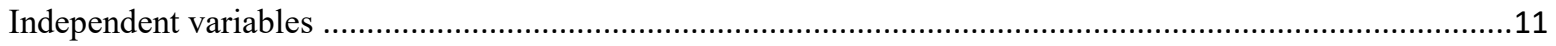

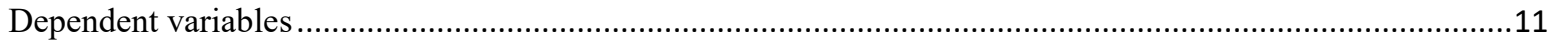

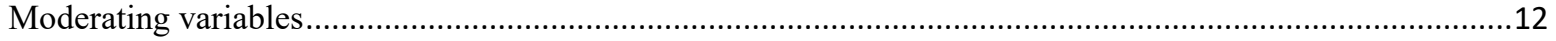

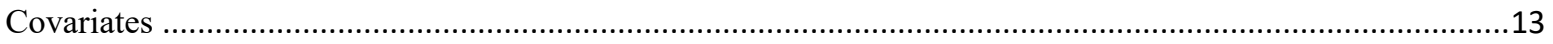

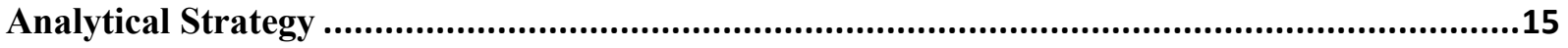

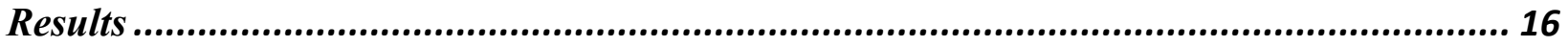

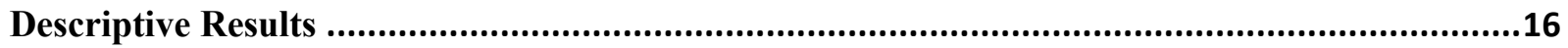

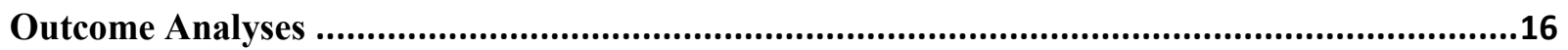

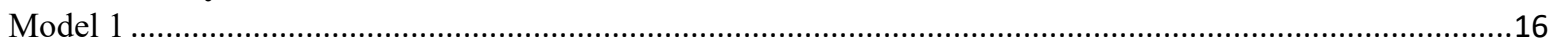

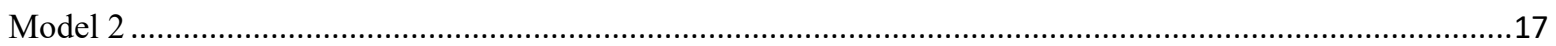

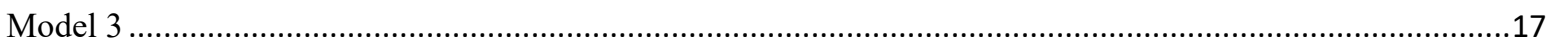

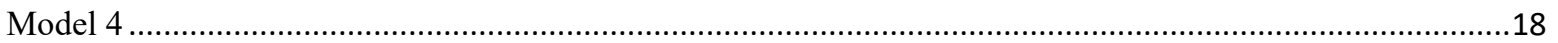

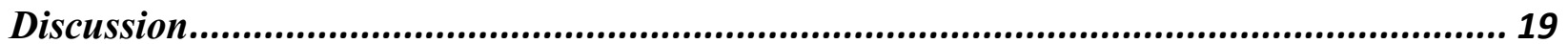

Residential Mobility and Adolescent Outcomes ..................................................................19

Moderation of Mother-Adolescent Relationship Characteristics..............................................20

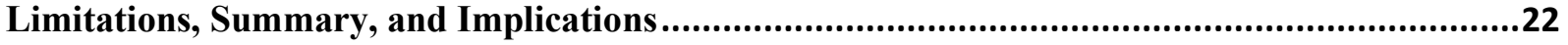

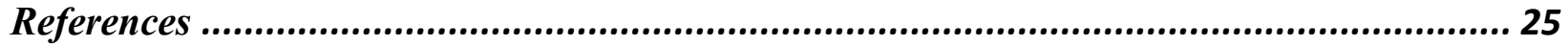

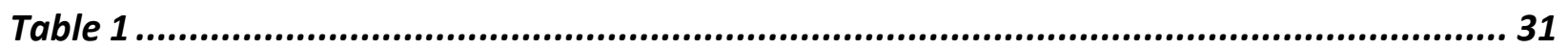

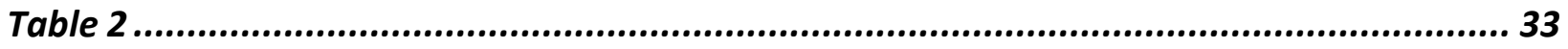

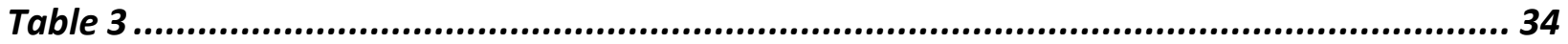

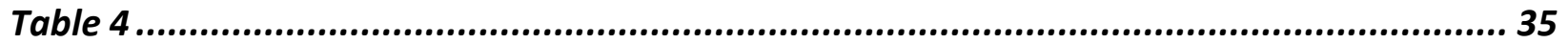

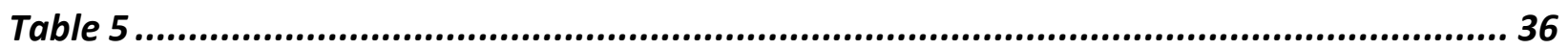

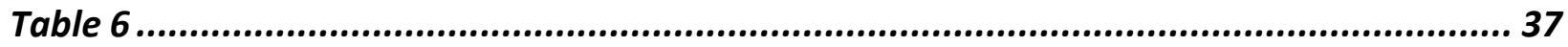

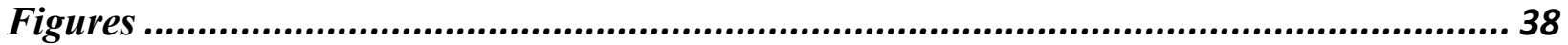

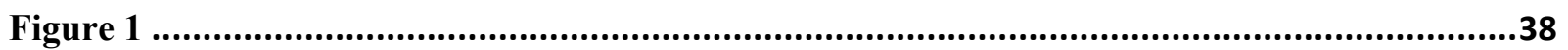

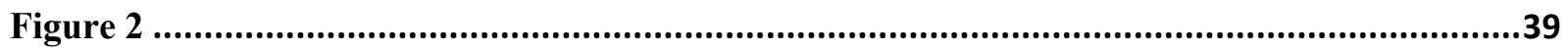




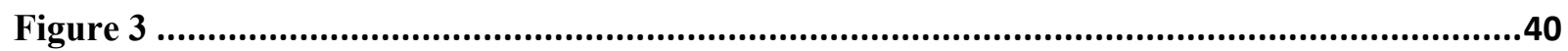

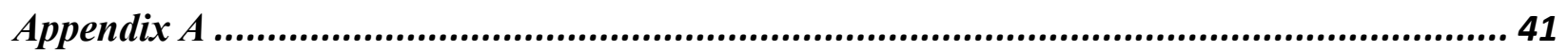

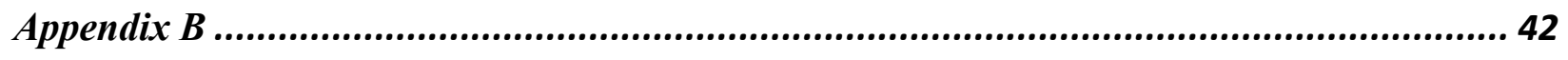

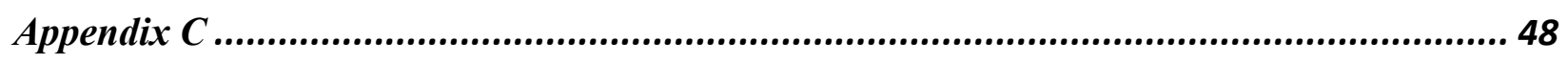

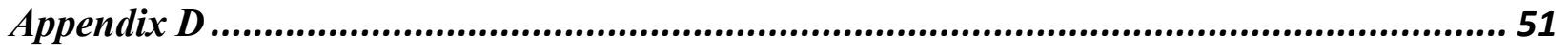

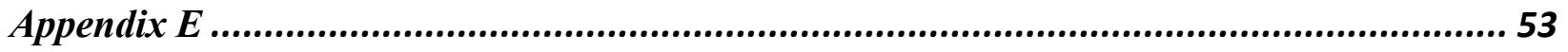

Appendix F ............................................................................................. 55

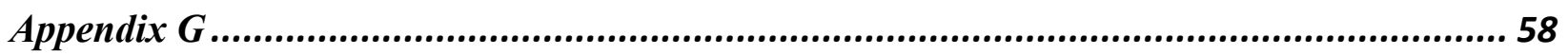

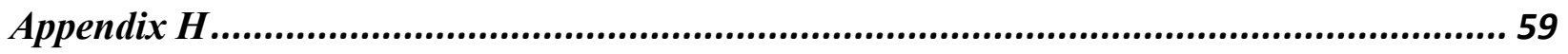

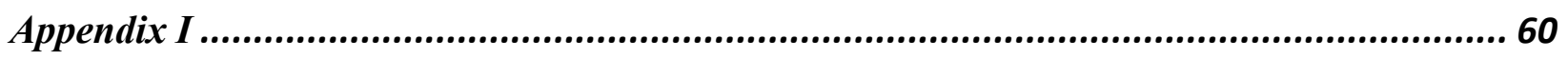

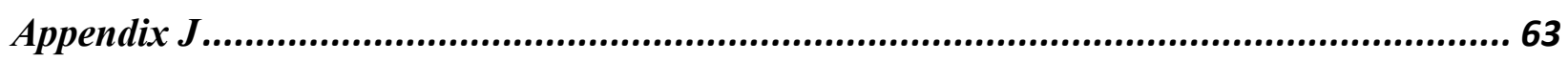




\section{Introduction}

According U.S. Census Bureau estimates, over 3 million children, ages 9-17, in the United States moved at least once in 2016 (U.S. Census Bureau, 2017). Research on residential mobility has suggested that adolescents who experience residential mobility have more adverse than favorable outcomes than adolescents who did not move (e.g., Anderson, Leventhal, Newman, \& Dupéré, 2014b). The consequences of mobility commonly examined by researchers include both short and long-term behavioral, academic, and health outcomes (Gillespie, 2017). Some outcomes commonly observed among residentially mobile adolescents are smaller social networks (South \& Haynie, 2004), poorer academic performance, and lower school engagement when compared with residentially stable adolescents (Haynie, South \& Bose, 2006). These adverse outcomes may result from the disruption experienced when a shift in environment occurs (e.g. Anderson et al., 2014b). Identifying supportive components of the adolescent's life when a change or multiple changes are occurring may help decrease the possibility of adverse outcomes associated with moving.

Adolescents who move experience a disruption in their life, but the relationship between the adolescent and parent has the potential to act as a buffer for the negative outcomes often associated with moving. Prior research suggests that close parent-adolescent relationships can influence behavior in positive ways (Gray \& Steinberg, 1999; Withers, McWey \& Lucier-Greer, 2016). Parent-child closeness was examined by Gillespie (2014) using data from the National Longitudinal Study of Youth (NLSY79). His findings suggest that the closer a child reports feeling to his/her parent, the fewer negative behavioral and/or academic outcomes the child may experience after moving. Examining the parent-adolescent relationship in the context of residential mobility is an important extension of Gillespie's (2014) findings. 
This study examined data from the year 15 wave of the Fragile Families and Child WellBeing Study (FFCW). The FFCW is a longitudinal study examining the environment and behavior of children born to unmarried mothers along with the well-being of the child throughout development. Participants in the year 15 wave include both the primary caregiver and focal child of each family. The fundamental idea behind the creation of the FFCW was to assess children's outcomes when born to an unmarried mother, so there was a disproportionate number of participants whose primary caregiver was their mother $(87.88 \%)$. For this reason, participants reporting their father or 'other' as the PCG will not be included in analyses $(n=434)$. In the present study, adolescents were classified as experiencing low mobility (1-2 moves), high mobility (more than 2 moves,) or as stable (did not move). The aim of this study was to assess adolescent behavioral outcomes following a move and to determine whether aspects of the mother-adolescent relationship moderate the relation between residential mobility and behavioral outcomes. This notion is congruent with previous research that suggests residential mobility during adolescence is associated with adverse behavioral outcomes following a move (e.g. Haynie et al., 2006) and parent-child relationship quality may mitigate the adverse effects of moving on children (Gillespie, 2014; Hagan, MacMillan, \& Wheaton, 1996)

\section{Theoretical Approach}

Residential mobility has the potential to disrupt an adolescent's environment, which is important during this developmental period as teens are spending more time outside of the home with their peers (Smetana, Robinson \& Rote, 2015). Adolescents are socialized by various persons such as family members (siblings, parents, relatives), classmates, teachers, and neighbors. Each of these contexts may be disrupted following a move, potentially contributing to changes in developmental outcomes. The parent-child relationship may then be particularly 
important in the context of a residential move. As parents spend the most time with the child throughout their development, parent-child relationships are influential in adolescent behavioral outcomes (Steinberg \& Morris, 2001).

In life course theory, Elder argues that development is cumulative over the life span (Elder, 1998). His theory addresses turning points, the importance of timing, and the principle of linked lives to help explain development. Turning points describe events that disrupt and change the life course, such as moving. A move has the potential to influence later development due to potential changes in social ties, academic opportunities, or changes in family strcuture. Each move an adolescent experiences has the potential to interrupt development, suggesting multiple moves may lead to more disruption in one's develomental trajectories. Moreover, the outcomes associated with a move may also be contingent upon the developmental timing (or stage) moving occurs (Anderson, Leventhal, \& Dupéré 2014a; Gillsepie, 2013). Research examining residential mobility suggests adolescents experience greater internalizing behaviors when compared to stable adolescents, but youth in early and middle childhood were not associated with greater internalizing behaviors when compared to stable children (Anderson et al., 2014a). The third principle of life course theory, linked lives, explains the interdependence of individuals and focuses on the importance of network ties. As touched on previously, the community the adolescent is in (or linked in), influences their developmental outcomes. Removing an adolescent from this community, through the process of moving, has the potential to disrupt their developmental outcomes. As the parent-adolescent relationship may remain a constant link following a move, the role this specific relationship plays is worth examining for positive or negative influences.

In summary, life course theory suggests that changes throughout one's life have the 
potential to influence later outcomes in positive or negative ways. Therefore, prior research suggesting negative developmental outcomes associated with a residential move illustrate the later developmental outcomes impacted by a turning point as described by Elder (1998). The examination of the parent-adolescent realtionship addresses the conecpt 'linked lives' and how the linked relationshp may impact one's development. The present study will examine residentially mobile adolescents' behavioral outcomes and the mother-adolescent relationship demonstrating the process described in the life course theory proposed by Elder (1998).

\section{Residential Mobility in Adolescence}

Prior research suggests that residential mobility during adolescence is associated with more adverse outcomes following a move than during any other developmental period (Anderson \& Leventhal, 2017; Goldberg, 1980). Prior research has examined an array of outcomes.

Prior work suggests mobile adolescents express higher rates of depression than their stable peers in analyses using data from the National Longitudinal Study of Adolescent Health (Add Health; Fowler, Henry, \& Marcal, 2015; Haynie \& South, 2005). Data from the NICHD Study of Early Child Care and Youth Development (NICHD SECCYD), suggests mobile adolescents experienced significantly greater internalizing behavior when compared to stable adolescents but only marginally for externalizing behaviors (Anderson et al., 2014a). When the number of moves experienced during adolescence is considered, those who experienced multiple moves ( $>1$ moves) display more externalizing behaviors than adolescents who did not move even when controlling for behavior prior to moving (Anderson \& Leventhal, 2017). In the same study, adolescents who moved less frequently ( 1 move) did not display significantly more externalizing and internalizing behaviors than stable adolescents. Adam and Chase-Lansdale (2002) examined a sample of female African-American adolescents and found the number of times moved was a 
significant predictor of externalizing behavior, where the more moves experienced, the greater the externalizing behavior. The same study found no association between mobility and internalizing behavior. These findings suggest mobile adolescents do experience, to some degree, worse outcomes in regard to internalizing and externalizing behaviors especially when the frequency of moves is considered.

Prior research concerning residentially mobile adolescents has also considered the delinquent outcomes of those who move compared to those who do not. Researchers examining the frequency of adolescent arrests using data from the National Longitudinal Study of Adolescent Health (Add Health) found residentially mobile adolescents were more likely to be arrested than their stable peers (Fowler et al., 2015). A study using NLSY79 data found residentially mobile adolescents reported significantly higher levels of involvement in violence than stable adolescents (Haynie \& South, 2005; Gillespie, 2013). Additional research with the NLSY79 found mobile adolescents were 23\% more likely to take part in delinquent behaviors than adolescents who had not experienced residential mobility (Gasper, DeLuca, \& Estacion, 2010). There is consistency across prior studies suggesting residentially mobile adolescents are more involved with delinquent behaviors and acts than stable adolescents. Less is known about the number of moves, a contribution of the present study.

\section{Mother-Adolescent Relationship}

As prior work suggests, residentially mobile adolescents frequently demonstrate increases in internalizing, externalizing, and delinquent behaviors. Outcomes associated with residential mobility in adolescence may be moderated by aspects of the parent-adolescent relationship (for a review of the behavioral outcomes associated with parent-adolescent relationships, see Steinberg $\&$ Morris, 2001). The parent-adolescent relationship, specifically with mothers, may moderate 
the outcomes of adolescents following a residential move.

Adolescence is a time of marked change and transition in adolescents' social domains, yet a period when parents remain an important feature. Parents who are warm, firm, and accepting of adolescent needs for psychological autonomy are, more often than not, associated with the most desirable behavioral outcomes in adolescent functioning (e.g. prosocial behavior, self-control, cheerfulness, and self-confidence; Gray \& Steinberg, 2001; Steinberg \& Morris, 2001). Furthermore, parents' ability to grant adolescents more autonomy may act as a protective factor against undesirable behaviors in adolescence.

Mother-adolescent relationship quality has been noted as an important factor for adolescent internalizing and externalizing problems. The quality of relationships is examined in a variety of ways so it is important for researchers to be cognizant of how they are defining parent-adolescent relationship qualities (Stattin \& Kerr, 2000). Fanti, Henrich, Brookmeyer, and Kuperminc (2008) conducted a study examining internalizing and externalizing behavior problems in relation to mother-adolescent relationship quality. Higher relationship quality was conceptualized as one of trust, communication, and a lack of alienation with the mother. Results suggested there was a significant association between adolescents' relationship quality with mothers and internalizing and externalizing behaviors, suggesting better maternal relationship quality is associated with lower levels of internalizing and externalizing problems (Fanti et al., 2008). Maternal-reported relationship quality also was found to be a predictor of adolescent internalizing and externalizing behavior in sample from the Longitudinal Studies of Child Abuse and Neglect when adolescents were 12-14 years old (McWey, Claridge, Wojciak, LettenbergerKlein, 2015). On the other hand, lower-quality mother-adolescent relationships have been associated with higher levels of externalizing and internalizing behaviors among adolescents 
(McKinney \& Renk, 2011). In summary, research concerning internalizing and externalizing behaviors in connection to relationship quality is consistent, where better relationship qualities inhibit the presence of internalizing and externalizing behaviors.

Parental monitoring, or the extent to which parents are cognizant of adolescent behavior and location, also has been examined in conjunction with adolescent behavior (Dishion \& McMahon, 1998). Researchers found high levels of parental awareness and monitoring were significantly related to lower levels of delinquent behaviors. Prior research also suggests the absence of parental monitoring is associated with greater internalizing and delinquency (Ingoglia, Lo Coco, Liga, \& Lo Cricchio, 2011). Researchers examining the Child Development Project found that high levels of parental monitoring were associated with low levels of delinquent behavior during adolescence compared with low levels of parental monitoring (Pettit, Laird, Dodge, \& Bates, 2001). The same inverse relationship has been found in regard to parental monitoring and adolescent internalizing behavior (Kerr \& Stattin, 2000). In a metaanalytic review of the relationship between parenting and delinquency during adolescence, parental monitoring had a significant negative relationship with delinquency, where greater monitoring led to less delinquent behavior (Hoeve, et al., 2009). These findings are consistent with other studies examining the influence parental monitoring has on adolescents' development of delinquent and antisocial behavior problems (Crouter \& Head, 2002; Dishion \& McMahon, 1998).

Limited research has examined the role of mothers in the context of residential mobility, but those that have suggest the importance of mothers in relation to residentially mobility. Gillespie (2014) examined the role mother-child closeness plays in counteracting the negative outcomes associated with moving ( $M$ age $=10.8$ years). Using data from the NLSY79, results 
suggested that the increased behavior problems (encompassing depressed/withdrawn, antisocial, and impulsive behaviors) noted among residentially mobile children may be buffered by the reported level of emotional closeness to one's mother over and above other child and family characteristics. Gillespie (2015) also examined changes in the parent-adolescent relationship following a move. Following a residential move, Gillespie found positive and negative changes in mother-adolescent relationships. Prior research has also suggested mothers are a form of social support with residentially mobile adolescents in relation to adolescent depression levels (Hendershott, 1989). Support from the adolescents' mother was a significant predictor of residentially mobile adolescents' depression scores, such that support from mothers was associated with lower depression scores among adolescents.

Limited research has examined the mother-adolescent relationship as a buffer for negative outcomes associated with residential mobility. Examining the influence of a potential constant during a residential move, the mother, is warranted. The purpose of this study is to explore how elements of the relationship may interact with residential mobility to influence internalizing, externalizing, and delinquent behaviors among residentially mobile adolescents.

\section{The Present Study}

The current study examines the internalizing, externalizing, and delinquent behaviors of adolescents who experience high and low rates of residential mobility compared to stable adolescents. Furthermore, elements of the mother-adolescent relationship are examined to determine if aspects of the relationship moderate the observed outcomes following a residential move. Specifically, I examine closeness and the degree to which the mother sets limits for the adolescent (parental monitoring). The following research questions are addressed: 1) Do adolescents who experience high and low rates of residential mobility display more internalizing, 
externalizing, and delinquent behaviors than stable adolescents? 2) Do aspects of the motheradolescent relationship (degree of closeness and parental monitoring) moderate the association between residential mobility and adolescent outcomes? I will address this question using the Fragile Families and Child Wellbeing study, which is a sample consisting of adolescents, at the time or birth, were born to unmarried mothers and are considered at risk for developmental outcomes.

From the theoretical framework and previous research, it is expected that residentially mobile adolescents will display more internalizing, externalizing, and delinquent behaviors than stable adolescents. Specifically, adolescents experiencing high and low residential mobility will show more internalizing, externalizing, and delinquent behaviors than stable adolescents.

Mother-adolescent closeness is expected to moderate the associations between residential mobility and adolescent behavior. Based on the review of literature concerning motheradolescent relationship quality, it is expected that adolescents experiencing high residential mobility, with high quality mother-adolescent relationships will exhibit significantly higher internalizing, externalizing, and delinquent behaviors than adolescents experiencing high residential mobility with lower quality mother-adolescent relationships.

Parental monitoring is also expected to moderate the aforementioned associations. As prior work suggests, some degree of autonomy given during adolescence can be protective against undesirable outcomes. It is expected that higher levels of parental monitoring will buffer adverse effects from the disruption of residential mobility. Therefore, high residential mobility among adolescents who report higher levels of limit setting will display fewer internalizing, externalizing and delinquent behaviors, than adolescents experiencing high residential mobility with lower levels of parental monitoring. 


\section{Method}

\section{Participants and Procedures}

The research questions will be addressed using data from the Fragile Families and Child Well-Being Study (FFCW). Since the focal child's birth between 1998 and 2000, nearly 5,000 families were followed to gather data concerning the development of children born to unmarried mothers. Participants are from large U.S. cities, such as Oakland, CA, Boston, MA, Detroit, MI, Pittsburgh, PA, and Toledo, $\mathrm{OH}$ (for more information concerning the initial data collection and a complete list of cities, see McLanahan, Garfinkel, \& Waller, 2000). The data for the FFCW study consists of interviews with both mothers, fathers, and/or primary caregiver at birth and again when the focal child is one, three, five, nine, and fifteen year(s) old.

For the current study, data from the years 9 and 15 wave were used. Year 15 data collection took place from 2014 to 2017 . Data collection was divided into four parts and includes: Primary Caregiver (PCG) Interviews (1-Hour Telephone Survey); Teen Interviews (1Hour Telephone Survey); and In-Home Surveys. For this analysis, only data from the PCG and teen interviews will be used. The PCG survey covers information concerning the teen's health and behavior, education, family life and parenting, household structure and family relationships, PCG health and behavior, social environment, informal support, parent's education, employment and income. As mentioned previously, only PCGs who reported themselves as the biological mother are being examined in this study. Teen surveys collected information on education and school experiences, family relationships, health and health behavior, and risky behaviors including sexual activity and substance use (McLanahan et al., 2000). To control for pre-move characteristics, three year 9 data variables (internalizing, externalizing, and delinquency) were merged with the year 15 wave and controlled for in the respective analyses (e.g. year 9 
internalizing was controlled for when including covariates in analyses).

The year 15 wave follows over 3,000 families. The sample had a slight majority of male adolescents (51.64\%) and the average age was 15.58 years $(S D=0.77)$. Almost half of the adolescents reported their race as Black/African American, non-Hispanic (49.73\%). In regard to family characteristics, nearly $69 \%$ of families lived above the poverty line and $61 \%$ of mothers reported being unmarried at the year 15 assessment. A complete description of year 15 sample characteristics can be found in Table 1.

\section{Measures}

Independent variables. Residential mobility was defined using a dummy variable from the PCG year 15 survey asking PCGs if the focal child moved since the last interview (year 9). PCGs were also asked how many times the focal child had moved since the last interview. A histogram outlining the number of moves adolescents experienced can be found in Figure 1. Responses were used to construct a mobility frequency variable, grouping adolescents into one of three mobility groups. High residential mobility was coded as 2 for adolescents who experienced more than 2 moves since the last interview. Low residential mobility was coded as 1 for adolescents who experienced 1-2 moves since the last interview and adolescent who did not move were placed into the stable group and categorized as 0 .

Dependent variables. Data concerning the teen's internalizing and externalizing behavior were collected using questions from the year 15 survey adapted from the Child Behavior Checklist /6-18 (CBCL; Achenbach \& Rescorla, 2001). The PCG was asked to rate their child's behavior for 28 statements using a Likert scale where 1=Not true and 3=Often true and were recoded for data analysis. The statements address anxious, depressed, withdrawn, aggressive, and rule-breaking behaviors that adolescents may exhibit (e.g. child gets in many 
fights; child is unhappy, sad or depressed). Internalizing and externalizing behaviors were assessed using subscales calculated by averaging item scores, where higher scores indicate more problematic behavior. The internalizing score was composed of responses to 8 statements $(\alpha=.79)$ and the externalizing score was composed of responses to 20 statements $(\alpha=.88)$. Individual scores were only calculated for participants with no missing responses. If a participant did not respond to one of the items, their overall score for internalizing or externalizing is considered missing. Year 9 internalizing and externalizing scores (also adapted from CBCL) were lagged to control for pre-move characteristics.

Teen delinquent behaviors were assessed using year 15 survey questions adapted from the National Longitudinal Study of Adolescent Health (Add Health). Adolescents were asked to rate the frequency of their delinquent behaviors (i.e. use of cigarettes, alcohol, and other illegal or prescription drugs) as never, 1 or 2 times, 3 or 4 times, or 5 or more times. Responses were summed for a total delinquency score, where higher scores represent higher levels of delinquent behavior. Cronbach's Alpha was calculated using the variables gathered to form the score $(\alpha=.75)$. Year 9 delinquency scores were also lagged to control for pre-move characteristics. However, the same questions were not assessed. The year 9 interview adapted survey items from the Things That You Have Done Scale (Maumary-Gremaud, 2000) and teens answered in a "YES/ NO" format as opposed to the Likert scale used in year 15. Responses for delinquent behavior items were summed to yield a total delinquent behavior score where higher scores indicate more crimes against people, theft, vandalism, alcohol use, and drug use reported by the focal child $(\alpha=.70)$. Mean scores of the sample for each outcome by mobility group can be found in Figure 2.

Moderating variables. Moderating variables focus on characteristics of the mother- 
adolescent relationship. PCG reported closeness to the adolescent as well as teen and PCG reported parental monitoring for the adolescent were all assessed during year 15 interviews.

For the mother-adolescent closeness measure, mothers were explicitly asked to rate the closeness between teen and mother using a Likert scale ranging from 1 (extremely close) to 4 (not very close) $(\alpha=.62)$. Responses were reverse coded so higher scores indicate a stronger relationship between mother and adolescent.

Parental monitoring questions were adapted from the NLSY97 and were labeled as PCG limit setting. Three questions asked who set rules or limits for the child regarding how late the child can stay out at night, what shows and movies the child can watch, and who the child can hang out with. The mother and teen selected separate responses from the options given: parent or parents decide, child decides for self, and parents and child decide jointly. Responses were recoded, where youth sets limits $=0$; limit set jointly $=1$; and parents set limits $=2$ and summed separately for mother and teen responses. The scale ranged from 0 (youth sets all limits) to 6 (parent sets all limits), with higher scores indicating greater parental monitoring. This created two constructed variables to be used as potential moderators: mother reported parental monitoring $(\alpha=.46)$ and teen reported parental monitoring $(\alpha=.49)$.

Covariates. Covariates include year 15 maternal reported depression, family’s socioeconomic status, PCG education level, race, age, relationship between biological parents, relationship between PCG and partner, and gender. These variables are in line with prior work examining FFCWS and the mechanisms that may influence developmental outcomes (Waldfogel, Craigie, \& Brooks-Gunn, 2010).

In the PCG interview, the mother reported on depressive symptoms within the last 6 months. This questionnaire was adapted from Composite International Diagnostic Interview- 
Short Form (CIDI-SF), Section A (Keesler, Andrews, Mroczek, Ustun, \& Wittchen, 1998). PCG were asked if they have had feelings of depression or anhedonia in the past year that lasted for at least two weeks and, if so, whether they symptoms lasted most of the day and occurred every day of the two-week period. If mothers responded yes, they were questioned further about 1) losing interest, 2) feeling tired, 3) change in weight, 4) trouble sleeping, 5) trouble concentrating, 6) feeling worthless, and 7) thinking about death. The data file for year 15 contained constructed dichotomous variables for a conservative and liberal version of diagnosis for major depression over the past year. The liberal diagnosis was used for the purposes of this study and follows Kessler and Mroczek's criteria (Keesler et al., 1998), requiring the respondent to report on twoweeks of depressive symptoms that last at least half the day.

Socioeconomic status was determined by the ratio of total household income to the official poverty thresholds established by the U.S. Census Bureau. The poverty threshold depends on the year and the number of people in the household. For each year that interviews were conducted, the prior year Census Bureau thresholds were used. Participants were categorized into one of the follow categories: less than 49\%, 50-99\%, 100-199\%, 200-299\%, or greater than $300 \%$.

Adolescent and maternal characteristics were also used as control variables. One of the questions in the PCG interview during year 15 asked mothers to report their current education level. The adolescent's age was also a constructed variable provided in the data set along with a constructed variable for the teen's race and ethnicity, which was created from previously established dummy variables for census-recognized racial and ethnic categories. Teens were either coded as white only (non-Hispanic), black/African American only (non-Hispanic), Hispanic/Latino, other only (non-Hispanic), or multi-racial (non-Hispanic). A dichotomous 
variable was provided in the dataset that described whether the biological parents were married or not. The data set also provides a different dichotomous variable identifying whether the PCG is in a married to a new partner. Additional variables were also available to determine the relationship quality between the biological parents and the PCG with the new partner (teen reported). Both of these were measured using a Likert scale where $1=$ poor and $5=$ excellent. Gender information merged from the first wave of data was also used as a covariate, where males were categorized as 1 and females categorized as 2 .

\section{Analytical Strategy}

As a first step, descriptive statistics were calculated for all variables being used to assess the amount of missing data. In addition, there was a large amount of missing data for the variables being used in this study ranging from 120-1,206 missing responses1. Multiple imputation was used to replace missing information. This approach for handling missing data is important because it allows for incomplete cases that would have been excluded from analysis to be completed and can minimize bias due to non-response (Little \& Rubin, 1989). Multiple imputation using STATA was conducted using 20 imputations.

Next, ordinary least squares regressions were used to analyze associations between mobility status and internalizing, externalizing and delinquent behaviors. The first set of model regressions examine if there were significant associations between mobility status (high mobility and low mobility v. stability) and the three behavioral outcomes (internalizing, externalizing, delinquency). A second set of models incorporated covariates mentioned previously into the regressions in a statistical attempt to mitigate any selection bias between the mobility groups and

\footnotetext{
${ }^{1}$ This range of missing responses does not include PCGs relationship quality to new partner, a covariate used on models 2 and 4. This particular variable was missing 2,315 observations. This is expected as 2,571 PCGs reported not being married to a new partner. Variables concerning PCGs being in a relationship with a new partner were not included in analyses.
} 
account for pre-move characteristics. The third set of models tested the possibility of interactions between each mobility group and mother-adolescent relationship characteristics. This model will determine if there are significant interactions between the mobility status and each of the following constructed relationship characteristics: 1) mother reported relationship closeness to teen, 2) teen reported parental monitoring, and 3) mother reported parental monitoring. A fourth and final set of models will add covariates to the three interactions tested in the previous model to mitigate the potential influence of selection bias and pre-move characteristics on the outcomes being examined.

\section{Results}

\section{Descriptive Results}

More than half of the sample had moved at least once since the year 9 interview $(62 \%)$. Most adolescents moved 1-2 times in the past 6 years $(44.47 \%)$ and $17.53 \%$ of adolescents moved more than twice since year 9 interviews. Descriptive information on all variables used in analyses can be found in Table 1 .

\section{Outcome Analyses}

Multiple regression analyses were used to test if residential mobility status significantly predicted adolescents' internalizing, externalizing, and delinquent behavior outcomes at year 15 . In addition, models were run to examine whether the association between residential mobility status and outcomes was moderated by parental closeness and monitoring. Models were run in a stepwise fashion such that the main independent variables were first included, followed by covariates and moderators.

Model 1. The relation between residential mobility status and outcomes varied by outcome under investigation. Residential mobility was a significant predictor of internalizing, 
externalizing, and delinquency without covariates. High residential mobility was significantly associated with higher levels of internalizing $(B=.06, S E=.03, p<.001)$, externalizing $(B=.10$, $S E=.01, p<.001)$, and delinquent $(B=.66, S E=.13, p<.001)$ behaviors at year 15 (compared to stable adolescents). Adolescents who experienced higher rates of mobility displayed more internalizing, externalizing, and delinquent behaviors than stable adolescents. Adolescents who experienced low residential mobility displayed significantly more externalizing $(B=.10, S E=.01$, $p<.001)$ and delinquent behaviors $(B=.39, S E=.10, p<.001)$ at year 15 than stable adolescents. These results are presented in Table 2 .

Model 2. Next, covariates were added into the model to mitigate any selection bias. Residential mobility was no longer a significant predictor for internalizing behaviors when including covariates. Moving remained a significant predictor for externalizing, but only for the high residential mobility group $(B=.05, S E=.01, p<.001)$ compared with the stable group. The same was true for delinquency, such that the high residential mobility group was a significant predictor $(B=.18, S E=0.13, p<.01)$ when compared to the stable group. The results for model 2 analyses are presented in Table 3.

Model 3. Next, multiple regression analysis was used to test the possibility of statistical moderation between mobility status and the following parent-adolescent relationship characteristics: 1) mother reported relationship closeness to teen, 2) mother reported parental monitoring, and 3) teen reported parental monitoring.

There was a significant interaction between mother reported closeness and mobility for externalizing behaviors only $(B=.51, S E=.04, p<.001)$. Interaction coefficients suggest, both low $(B=0.12, S E=.01, p<.05)$ and high residential mobility $(B=.24, S E=.02, p<.001)$ interact with relationship closeness in predicting externalizing behaviors at year 15 . Results can be found in 
Table 4 for year 15 adolescent outcomes by mobility group and mother reported closeness to the adolescent.

For mother reported parental monitoring, there was only a significant interaction with high residential mobility on delinquency $(B=-.22, S E=.10, p<.05)$, such that adolescents' who experienced higher rates of residential mobility and less monitoring had greater delinquency tendencies than adolescents with higher rates of residential mobility and more limitations. Results can be found in Table 5 .

No evidence of moderation was found for teen-reported parental monitoring.

Model 4. Once covariates were included in the models, closeness between the mother and adolescent relationship continued to significantly interact with mobility status, but there was no evidence of moderation for either parental monitoring variables.

Parental closeness moderated the relation between residential mobility status and externalizing behavior $(B=0.83, S E=.10, p<.001)$. High residential mobility $(B=-04, S E=.02$, $p<.01)$ interacted with parent-adolescent relationship closeness. Low residential mobility $(B=-$ $.03, S E=.01, p<.05)$ also interacted with parent-adolescent relationship closeness. Results for the interaction between closeness and mobility on outcomes can be found in in Table 6. As shown in Figure 3 adolescents who experienced high residential mobility and have a closer relationship with their parent displayed less externalizing behaviors than highly mobile adolescents with less close parent-adolescent relationships.

In summary, the results from this study suggest the presence of internalizing, externalizing, and delinquent behaviors following a move is contingent upon how many moves an adolescent experienced, mother and adolescent characteristics, as well as specific characteristics of the parent-adolescent relationship. 


\section{Discussion}

The purpose of the current study was to contribute to the research examining the adverse outcomes (internalizing, externalizing, and delinquent behaviors) associated with residential mobility during adolescence and the role of parenting in those relations. Adolescents were identified as experiencing high residential mobility (more than 2 moves), low residential mobility (1-2 moves) and as stable (0 moves). Mother-adolescent relationship closeness and parental monitoring were examined separately as potential moderators of the relationship between residential mobility and adolescent outcomes. As prior research suggests, positive characteristics of the mother-adolescent relationship may benefit adolescents who are at risk for adverse outcomes (Withers, et al. 2016)

\section{Residential Mobility and Adolescent Outcomes}

I hypothesized that residentially mobile adolescents would display more internalizing, externalizing, and delinquent behaviors than adolescents who did not move. More specifically, the more residential mobility, the greater presence of internalizing, externalizing, and delinquent behaviors. The hypotheses were partially supported, even with the inclusion of covariates in the analyses to control for pre-existing differences between mobile- and non-mobile-families (Gasper et al., 2010; Haynie \& South, 2005). This study found higher levels of residential mobility ( $>2$ moves) were significantly associated with greater externalizing and delinquent behaviors when compared to stable adolescents. Lower rates of residential mobility (1-2 moves) had no significant influence on outcomes when controlling for pre-existing differences. These findings suggest that high rates of residential mobility are associated with adolescents' externalizing and delinquent behaviors even when pre-exiting differences are controlled for.

As reviewed, prior research examining the internalizing and externalizing behavioral 
outcomes of adolescents had inconsistent findings. My findings are in line with previous studies examining externalizing behavior in the context of frequency of moves (Anderson \& Leventhal, 2017; Adam \& Chase-Lansdale, 2002). However, it is also surprising that my sample did not find any differences in internalizing behavior between mobile and stable adolescents, as prior research suggests residentially mobile adolescents experiencing greater internalizing behaviors when compared to stable adolescents (Fowler et al., 2015; Haynie \& South, 2005). The lack of significance in my findings may be due to the internalizing behaviors of the adolescent being reported by the mother and not the adolescent. If internalizing behaviors were reported by the adolescent, the measures may be more accurate and significance may have presented itself as expected. This study's findings are also consistent with research examining residential mobility and delinquency outcomes, suggesting mobility is associated with higher levels of delinquency (Gasper et al., 2010; Gillespie, 2013; Fowler et al., 2015). However, no prior work, to my knowledge, has considered the frequency of moves and adolescent delinquency outcomes.

Importantly, the findings in the current study have relatively low significant effect sizes ( $B$ ranges from .05-0.35), which is similar to previous work (e.g. Haynie \& South, 2005). However, the effect size found for high residential mobility on delinquency, when controlling for pre-existing differences, was higher than previous research suggests (Gasper et al., 2010).

\section{Moderation of Mother-Adolescent Relationship Characteristics}

After examining adolescents' behavioral outcomes and residential mobility, motheradolescent relationship characteristics were examined as moderators. I expected that all three characteristics of the mother-adolescent relationship would moderate the relationship between mobility status and internalizing, externalizing, and delinquent behaviors. The hypotheses were partially supported. 
Closeness significantly interacted with both high and low residential mobility status in predicting externalizing outcomes as shown in Figure 3. When highly mobile adolescents' mothers reported a closer relationship, the adolescent had displayed significantly less externalizing behaviors than their highly mobile peers who's mothers identified a less close relationship. The same association was found for adolescents who experienced low mobility. My findings suggest mother's report of closeness between the parent and adolescent may serve as a protective factor against adolescents' externalizing behavior following one or more residential moves. This is in line with prior working suggesting mother-adolescent relationships moderate adolescent outcomes, specifically for externalizing behaviors (e.g. Fanti et al., 2008). This finding supported my hypothesis; however, effect sizes were small. A limitation to the closeness measure used, is that it is only from the adolescent's mother. Future research should consider using both teen and mother reports to examine if the perceptions have different interaction effects.

No significant evidence was found to support parental monitoring as a moderator. However, this may be due to the low reliability for teen and mother's reported parental monitoring. Teen's reported, on average, having more autonomy than what the mother perceived (teen PM $M=2.97, S D=1.46$ and mother PM $M=4.09, S D=1.34$ ). Future research may consider examining these two constructs in tandem, or the difference of the two, as a potential moderator. Lastly, perhaps there is more of a curvilinear effect in parental monitoring. As mentioned previously, parental monitoring tends to decrease in adolescence and more autonomy is granted. Future research could examine if joint decision making between the adolescent and mother is more beneficial for residentially mobile adolescents than either end of the spectrum (complete autonomy or high PM). 


\section{Limitations, Summary, and Implications}

There are several limitations to this study. The distance of a move (Gillespie, 2013), school mobility (Gasper et al., 2010), and school-turnover rate (South \& Haynie, 2004) have previously been associated with having heavy influences on residential mobility outcomes. The current study did not account for these influences. Future work examining residential mobility and parent-adolescent relationships should attempt to consider these factors as well. Recent stressors (i.e. other environmental changes) may also influence the associations between residential mobility status (frequency of moves) and adolescent outcomes, such as internalizing, externalizing, and delinquent behaviors.

Prior research also suggests there the quality of parent-adolescent relationships decreases during adolescence (Kerr, Stattin, \& Burk, 2010), even in regard to residential mobility (Gillespie, 2015). Furthermore, aspects of the parent-adolescent relationship may also be a result of the stress experienced from a move (Laird, Criss, Pettit, Bates, \& Dodge, 2009; Haynie \& Osgood, 2005), making residentially mobile adolescents even more susceptible to internalizing, externalizing and/or delinquent behaviors. Future research should consider examining how the parent-adolescent relationship changes following a move when considering characteristics of the relationship as a moderator. With my analyses, I cannot discuss how the relationship may have changed from year 9 to year 15 interviews.

Important limitations related to the sample under investigation also should be noted. Data were used from the FFCW which targeted participants who were born to unmarried mothers. At year 15 data collection, $61 \%$ of mothers still reported themselves as unmarried. Single parent households are at risk for a variety of adverse outcomes and may influence the outcomes being examined in this study (Hetherington, Cox, \& Cox, 1982; Manning \& Lamb, 2003). I attempted 
to mitigate the effects of selection bias by controlling for variables in line with Waldfogel, Craigie, and Brooks-Gunn's review of previous research concerning the FFCW (2010). Furthermore, this study may lack generalizability due to the unique sample used for data collection. This study also only examines mother-adolescent relationships and is therefore not applicable to adolescents whose PCG is their father or someone else. However, prior research suggests adolescents spend more time with mothers than fathers (Larson, Richards, Sims, \& Dworkin, 2001). The closeness measures is also only the perception of the mother and not the adolescent. Examining the adolescent's perception of closeness to the mother may produce difference results than found in this study.

As mentioned previously, this longitudinal survey did have large amounts of missing data, but the use of multiple imputation should help with this issue (Allison, 2001). The researcher could also not account for how many times the adolescent had moved prior to year 9 and previous research suggests mobility from early childhood should also be examined when considering adolescent residential mobility (Anderson \& Leventhal, 2017). Lastly, there is also a 6-year time span that mobility may have occurred in my sample. This makes it difficult to determine if the outcomes in this study are truly associated with adolescent's mobility or other factors that may have occurred in the past 6 years.

My results suggest adolescents who move (especially more than 2 times) are at risk for displaying greater externalizing behavior than adolescents who did not experience a residential move. In line with the life course theoretical framework, experiencing multiple residential moves may not only disrupt current behaviors, but also later developmental outcomes for the adolescent. Externalizing behaviors in adolescence have been linked to poor outcomes in adulthood such as anxiety problems and substance use and abuse (Moffitt, Caspi, Harrington, \& 
Milne, 2002; Reef, Diamantopoulou, van Meurs, Verhulst, \& van der Ende, 2011; Ferguson, Horwood \& Ridder, 2007). Adolescents' externalizing behaviors should be concerning to parents, teachers, and other professionals. Interventions and support may be implemented for adolescents who are at-risk due to their residential mobility status. This study suggests the parent-adolescent relationship may be one support. Schools should be cognizant of the rates at which their students are experiencing residential mobility in their school so they may provide the proper information on the effects of residential mobility to families. 


\section{References}

Achenbach, T. M., \& Rescorla, L. (2001). ASEBA school-age forms \& profiles.

Adam, E. K., \& Chase-Lansdale, P. L. (2002). Home sweet home (s): parental separations, residential moves, and adjustment problems in low-income adolescent girls. Developmental psychology, 38(5), 792.

Allison, P.D. (2001). Missing data. Thousand Oaks, CA: Sage.

Amato, P. R., \& Sobolewski, J. M. (2004). The effects of divorce on fathers and children. In M. E. Lamb (Ed.), The role of the father in child development (pp. 341-367). New York: Wiley.

Amato, P. R., \& Sobolewski, J. M. (2004). The effects of divorce on fathers and children. In M. E. Lamb (Ed.), The role of the father in child development (pp. 341-367). New York: Wiley.

Anderson, S., \& Leventhal, T. (2017). Residential Mobility and Adolescent Achievement and Behavior: Understanding Timing and Extent of Mobility. Journal Of Research On Adolescence (Wiley-Blackwell), 27(2), 328-343. doi:10.1111/jora.12288

Anderson, S., Leventhal, T., \& Dupéré, V. (2014a). Residential mobility and the family context: A developmental approach. Journal of Applied Developmental Psychology, 35(2), 70-78.

Anderson, S., Leventhal, T., Newman, S., \& Dupéré, V. (2014b). Residential mobility among children: A framework for child and family policy. Cityscape, 16(1), 5.

Crouter, A. C., \& Head, M. R. (2002). Parental monitoring and knowledge of children. Handbook of parenting, 3, 461-483.

Dishion, T. J., \& McMahon, R. J. (1998). Parental monitoring and the prevention of child and adolescent problem behavior: A conceptual and empirical formulation. Clinical child and family psychology review, 1(1), 61-75.

Elder, G. H. (1998). The life course as developmental theory. Child development, 69(1), 1-12. 
Fanti, K. A., Henrich, C. C., Brookmeyer, K. A., \& Kuperminc, G. P. (2008). Toward a transactional model of parent-adolescent relationship quality and adolescent psychological adjustment. The Journal of Early Adolescence, 28(2), 252-276.

Fowler, P. J., Henry, D. B., \& Marcal, K. E. (2015). Family and housing instability: Longitudinal impact on adolescent emotional and behavioral well-being. Social science research, 53, 364-374.

Gasper, J., DeLuca, S., \& Estacion, A. (2010). Coming and going: Explaining the effects of residential and school mobility on adolescent delinquency. Social Science Research, 39(3), 459-476. doi:10.1016/j.ssresearch.2009.08.009

Gillespie, B. J. (2013). Adolescent behavior and achievement, social capital, and the timing of geographic mobility. Advances in life course research, 18(3), 223-233.

Gillespie, B. J. (2014). Does Intergenerational Solidarity Buffer the Negative Effects of Residential Mobility?. Evidence for US children. Field Action Science Reports.

Gillespie, B. J. (2015). Residential mobility and change and continuity in parenting processes. Journal of Research on Adolescence, 25(2), 279-294.

Gillespie, B. J. (2017). Household Mobility in America Overview and Conclusion. In Household Mobility in America (pp. 241-256). Palgrave Macmillan, New York.

Goldberg, E. R. (1980). Relocation and the family: A crisis in adolescent development. In Uprooting and development (pp. 211-231). Springer, Boston, MA.

Gray, M. R., \& Steinberg, L. (1999). Unpacking authoritative parenting: Reassessing a multidimensional construct. Journal of Marriage and the Family, 574-587.

Hagan, J., MacMillan, R., \& Wheaton, B. (1996). New kid in town: Social capital and the life course effects of family migration on children. American Sociological Review, 61(3), 
368-368. doi:10.2307/2096354

Haynie, D. L., \& Osgood, D. W. (2005). Reconsidering peers and delinquency: How do peers matter?. Social Forces, 84(2), 1109-1130.

Haynie, D. L. \& South, S. J. (2005). Residential Mobility and Adolescent Violence. Social Forces 84(1), 361-374. Oxford University Press. Retrieved January 21, 2018, from Project MUSE database.

Haynie, D. L., South, S. J., \& Bose, S. (2006). The company you keep: Adolescent mobility and peer behavior. Sociological Inquiry, 76, 397-426.

Hetherington, E. M., Cox, M., \& Cox, R. (1982). Effects of divorce on parents and children. Nontraditional families: parenting and child development/edited by Michael E. Lamb.

Hendershott, A. B. (1989). Residential mobility, social support and adolescent selfconcept. Adolescence, 24(93), 217.

Hoeve, M., Dubas, J. S., Eichelsheim, V. I., Van Der Laan, P. H., Smeenk, W., \& Gerris, J. R. (2009). The relationship between parenting and delinquency: A meta-analysis. Journal of abnormal child psychology, 37(6), 749-775.

Ingoglia, S., Lo Coco, A., Liga, F., \& Grazia Lo Cricchio, M. (2011). Emotional separation and detachment as two distinct dimensions of parent—adolescent relationships. International Journal of Behavioral Development, 35(3), 271-281.

Kessler, R. C., Andrews, G., Mroczek, D., Ustun, B., \& Wittchen, H. U. (1998). The World Health Organization composite international diagnostic interview short-form (CIDISF). International journal of methods in psychiatric research, 7(4), 171-185.

Kerr, M., \& Stattin, H. (2000). What parents know, how they know it, and several forms of 
adolescent adjustment: further support for a reinterpretation of monitoring. Developmental psychology, 36(3), 366.

Kerr, M., Stattin, H., \& Burk, W. J. (2010). A reinterpretation of parental monitoring in longitudinal perspective. Journal of Research on Adolescence, 20(1), 39-64.

Laird, R. D., Criss, M. M., Pettit, G. S., Bates, J. E., \& Dodge, K. A. (2009). Developmental trajectories and antecedents of distal parental supervision. The Journal of early adolescence, 29(2), 258-284.

Larson, R. W., Richards, M. H., Sims, B., \& Dworkin, J. (2001). How urban African American young adolescents spend their time: Time budgets for locations, activities, and companionship. American journal of community psychology, 29(4), 565-597.

Little, R. J., \& Rubin, D. B. (1989). The analysis of social science data with missing values. Sociological Methods \& Research, 18(2-3), 292-326.

Manning, W. D., \& Lamb, K. A. (2003). Adolescent well-being in cohabiting, married, and single-parent families. Journal of Marriage and Family, 65(4), 876-893.

McLanahan, S., Garfinkel, I., \& Waller, M. (2000). Fragile families and child wellbeing study. Eunice Kennedy Shriver National Institute of Child Health and Human Development (NICHD).

Maumary-Gremaud, A. (2000). Things that you have done. (Technical Report) http://www.fasttrackproject.org/techrept/t/tyd/tyd5tech.pdf

McKinney, C., \& Renk, K. (2011). A multivariate model of parent-adolescent relationship variables in early adolescence. Child Psychiatry \& Human Development, 42(4), 442-462.

McWey, L. M., Claridge, A. M., Wojciak, A. S., \& Lettenberger-Klein, C. G. (2015). Parentadolescent relationship quality as an intervening variable on adolescent outcomes among 
families at risk: Dyadic analyses. Family Relations, 64(2), 249-262.

Moffitt, T. E., Caspi, A., Harrington, H., \& Milne, B. J. (2002). Males on the life-coursepersistent and adolescence-limited antisocial pathways: Follow-up at age 26 years. Development and psychopathology, 14(1), 179-207.

Pettit, G. S., Laird, R. D., Dodge, K. A., Bates, J. E., \& Criss, M. M. (2001). Antecedents and behavior-problem outcomes of parental monitoring and psychological control in early adolescence. Child development, 72(2), 583-598.

Reef, J., Diamantopoulou, S., van Meurs, I., Verhulst, F. C., \& van der Ende, J. (2011). Developmental trajectories of child to adolescent externalizing behavior and adult DSMIV disorder: results of a 24-year longitudinal study. Social psychiatry and psychiatric epidemiology, 46(12), 1233-1241.

South, S., \& Haynie, D. (2004). Friendship networks of mobile adolescents. Social Forces, 83(1), 315-350.

Smetana, J. G., Robinson, J., \& Rote, W. M. (2015). Socialization in adolescence. Handbook of socialization: Theory and research, 60-84.

Stattin, H., \& Kerr, M. (2000). Parental monitoring: A reinterpretation. Child development, 71(4), 1072-1085.

Steinberg, L., \& Morris, A. S. (2001). Adolescent development. Annual review of psychology, 52(1), 83-110.

U.S. Census Bureau (2017). Current Population Survey, Annual Social and Economic Supplement

Waldfogel, J., Craigie, T. A., \& Brooks-Gunn, J. (2010). Fragile families and child wellbeing. The Future of children/Center for the Future of Children, the David and 
Lucile Packard Foundation, 20(2), 87.

Withers, M. C., McWey, L. M., \& Lucier-Greer, M. (2016). Parent-Adolescent Relationship Factors and Adolescent Outcomes Among High-Risk Families. Family Relations, 65(5), 661-672. 


\section{Table 1}

Means, Standard Deviations, and Percentages for Study Variables

\begin{tabular}{lcc}
\hline Characteristic & M or \% & (SD) \\
\hline Residential mobility type & & \\
$\quad$ Stable & 38.00 & \\
Low (1-2 moves) & 44.47 & \\
High (>2 moves) & 17.53 & \\
& & \\
Adolescent (age 15) Outcomes & & \\
Internalizing score & 0.25 & 0.31 \\
Externalizing score & 0.22 & 0.25 \\
Teen Delinquency score & 1.36 & 2.53
\end{tabular}

\section{Child characteristics}

Male

Age

Teen Race

White only, non-Hispanic

17.30

Black/African American

49.73

Hispanic/Latino

24.96

Other only, non-Hispanic

2.81

Multi-racial, non-Hispanic

5.20

\section{Maternal characteristics}

Depression

Education Level

Less than HS

HS or Equivalent

18.25

Some college, tech

44.43

College or grad

Poverty Category

$0-49 \%$

$50-99 \%$

17.64

$100-199 \%$

28.07

$200-299 \%$

14.59

$300 \%+$

26.09

\section{Family Structure}

Biological parents married

PCG married to new partner 


\begin{tabular}{lcc}
\hline Characteristic & M or \% & $(\boldsymbol{S D})$ \\
\hline Days a week dinner with family & 4.87 & 0.77 \\
Year 9 Characteristics & & \\
Internalizing score & 0.14 & 0.19 \\
Externalizing score & 0.77 & 2.77 \\
Delinquency score & 16.24 & 5.87 \\
& & \\
Mother-Adolescent Relationship & & \\
Mother reported closeness to teen & 3.51 & 0.69 \\
Teen report- limit setting & 2.97 & 1.46 \\
Mother report- limit setting & 4.09 & 1.34 \\
\hline
\end{tabular}

Note: $N=3,146$. Results combined across 20 imputed datasets. 


\section{Table 2}

Year 15 Adolescent outcomes by mobility group (in reference to stable adolescents).

\begin{tabular}{rrccc}
\hline & & Internalizing & Externalizing & $\begin{array}{c}\text { Self-Report } \\
\text { Delinquency }\end{array}$ \\
\hline \multirow{2}{*}{ Model 1 } & & $B(S E)$ & $B(S E)$ & $B(S E)$ \\
& Mobility Group & & & \\
& 1-2 Moves & $0.00(0.01)$ & $0.03(0.01)^{* * *}$ & $0.39(0.10)^{* * *}$ \\
& $>2$ Moves & $0.06(0.02)^{* * *}$ & $0.10(0.01)^{* * *}$ & $0.66(0.13)^{* * *}$ \\
\hline
\end{tabular}

Note: $N=3,146$. Results combined across 20 imputed datasets.

$+p<.10 . * p<0.05 . * * p<.01 * * * . p<.001$ 


\section{Table 3}

Year 15 Adolescent outcomes by mobility group (in reference to stable adolescents) with covariates.

\begin{tabular}{rccc}
\hline & Internalizing & Externalizing & $\begin{array}{c}\text { Self-Report } \\
\text { Delinquency }\end{array}$ \\
\hline Model 2 & $B(S E)$ & $B(S E)$ & $B(S E)$ \\
Mobility Group & & & \\
1-2 Moves & $-0.02(0.01)+$ & $0.00(0.01)$ & $0.18(0.10)+$ \\
>2 Moves & $0.01(0.02)$ & $0.05(0.01)^{* * *}$ & $0.35(0.13)^{* *}$ \\
\hline Covariates & & & \\
Maternal depression & $0.17(0.01)^{* * *}$ & $0.10(0.01)^{* * *}$ & $0.19(0.11)^{+}$ \\
SES & $0.00(0.00)$ & $-0.02(0.00)^{* * *}$ & $-0.08(0.04)^{*}$ \\
Maternal education & $0.00(0.01)$ & $0.00(0.00)$ & $-0.13(0.05)^{* *}$ \\
Teen race & $0.00(0.01)$ & $-0.01(0.00)$ & $0.03(0.05)$ \\
Age & $0.00(0.01)$ & $-0.01(0.01)$ & $0.14(0.06)^{*}$ \\
Child sex & $0.02(0.01)$ & $-0.04(0.01)^{* * *}$ & $-0.71(0.10)^{* * *}$ \\
Biological parents married & $0.02(0.02)$ & $-0.03(0.01)^{*}$ & $-0.13(0.14)$ \\
PCG with new partner & $0.03(0.02)+$ & $0.02(0.01)$ & $-0.12(0.13)$ \\
Biological parents' & $-0.03(0.01)^{* * *}$ & $-0.02(0.00)^{* * *}$ & $-0.16(0.05)^{* * *}$ \\
relationship quality & & & $-0.20(0.08)^{*}$ \\
with partner & $-0.01(0.01)+$ & $-0.02(0.01+$ & $-0.09(0.02)^{* * *}$ \\
Mothers relationship quality & & & - \\
Yamily & $0.00(0.00)$ & $0.00(0.00)$ & - \\
Yr9 Internalizing & $0.01(0.01)+$ & - & $-0.04(0.01)^{* * *}$ \\
Yr9 Delinquency & - & $0.00(0.00)+$ & -
\end{tabular}

Note: $N=3,146$. Results combined across 20 imputed datasets.

$+p<.10 . * p<0.05 . * * p<.01 * * * . p<.001$ 


\section{Table 4}

Year 15 Adolescent outcomes by mobility group and mother reported closeness

\begin{tabular}{rccc}
\hline & Internalizing & Externalizing & Self-Report Delinquency \\
\hline Model 3 & $B(S E)$ & $B(S E)$ & $B(S E)$ \\
& & & \\
Mobility Group & & & \\
1-2 Moves & $-0.08(0.06)$ & $0.12(0.05)^{*}$ & $0.39(0.10)^{* * *}$ \\
>2 Moves & $0.10(0.08)$ & $0.24(0.06)^{* * *}$ & $0.66(0.13)^{* * *}$ \\
& & & $-0.35(0.10)^{* * *}$ \\
Maternal reported closeness & $-0.10(0.01)^{* * *}$ & $-0.09(0.01)^{* * *}$ & \\
Interaction Variable & & & \\
Closeness X Mobility Group & & & $0.46(0.51)$ \\
1-2 Moves & $0.02(0.02)$ & $-0.03(0.1)+$ & $0.91(0.64)$ \\
$>2$ Moves & $-0.01(0.02)$ & $-0.04(0.02)^{*}$ & \\
\hline
\end{tabular}

Note: $N=3,146$. Results combined across 20 imputed datasets.

$+p<.10 .{ }^{*} p<0.05 . * * p<.01 * * * . p<.001$ 


\section{Table 5}

Year 15 Adolescent outcomes by mobility group and mother reported parental monitoring

\begin{tabular}{rccc}
\hline & Internalizing & Externalizing & $\begin{array}{c}\text { Self-Report } \\
\text { Delinquency }\end{array}$ \\
\hline Model 3 & $B(S E)$ & $B(S E)$ & $B(S E)$ \\
Mobility Group & & & \\
$1-2$ Moves & $0.05(0.04)$ & $0.08(0.03)^{*}$ & $0.97(0.32)^{* *}$ \\
$>2$ Moves & $0.10(0.05)+$ & $0.13(0.04)^{* * *}$ & $1.53(0.40)^{* * *}$ \\
Interaction Variables & & & \\
Mother reported parental & $-0.01(0.01)+$ & $0.00(0.01)$ & $0.07(0.05)$ \\
monitoring & & & \\
X Mobility Group & & $-0.01(0.01)$ & $-0.14(0.07)+$ \\
$1-2$ Moves & $-0.01(0.01)$ & $-0.01(0.01$ & $-0.22(0.10)^{*}$ \\
\hline 2 Moves & $-0.01(0.01)$ &
\end{tabular}

Note: $N=3,146$. Results combined across 20 imputed datasets.

$+p<.10 .{ }^{*} p<0.05 . * * p<.01 * * * . p<.001$ 
Table 6

Mother-adolescent relationship closeness $x$ mobility group on year 15 outcomes

\begin{tabular}{|c|c|c|c|}
\hline & Internalizing & Externalizing & $\begin{array}{l}\text { Self-Report } \\
\text { Delinquency }\end{array}$ \\
\hline & $B(S E)$ & $B(S E)$ & $B(S E)$ \\
\hline \multicolumn{4}{|l|}{ Model 4} \\
\hline \multicolumn{4}{|l|}{ Mobility Group } \\
\hline 1-2 Moves & $-0.10(0.06)+$ & $0.11(0.05)^{*}$ & $0.46(0.49)$ \\
\hline$>2$ Moves & $0.05(0.08)$ & $0.20(0.06)^{* * *}$ & $0.83(0.62)$ \\
\hline Mother reported closeness & $-0.09(0.01)^{* * *}$ & $-0.08(0.01)^{* * *}$ & $-0.22(0.10)^{*}$ \\
\hline \multicolumn{4}{|l|}{ Interaction Variable } \\
\hline \multicolumn{4}{|l|}{ Closeness X Mobility Group } \\
\hline 1-2 Moves & $0.02(0.02)$ & $-0.03(0.01)^{*}$ & $-0.08(0.14)$ \\
\hline$>2$ Moves & $-0.01(0.02)$ & $-0.04(0.02)^{* *}$ & $-0.14(0.17)$ \\
\hline \multicolumn{4}{|l|}{ Covariates } \\
\hline Maternal depression & $0.16(0.01)^{* * *}$ & $0.09(0.01)^{* * *}$ & $0.15(0.11)$ \\
\hline SES & $0.00(0.00)$ & $-0.02(0.0) * * *$ & $-0.08(0.04)^{*}$ \\
\hline Maternal education & $0.00(0.01)$ & $0.00(0.00)$ & $-0.14(0.05)^{* *}$ \\
\hline Teen race & $-0.01(0.01)$ & $-0.01(0.00)^{*}$ & $0.02(0.05)$ \\
\hline Age & $0.00(0.01)$ & $-0.01(0.01)$ & $0.14(0.06)^{*}$ \\
\hline Child sex & $0.03(0.01)^{*}$ & $-0.03(0.01)^{* * *}$ & $-0.69(0.10)^{* * *}$ \\
\hline Biological parents married & $0.02(0.02)$ & $-0.03(0.01)^{* *}$ & $-0.14(0.14)$ \\
\hline PCG with new partner & $0.03(0.02)+$ & $0.01(0.01)$ & $-0.13(0.13)$ \\
\hline $\begin{array}{r}\text { Biological parents' relationship } \\
\text { quality }\end{array}$ & $-0.03(0.01) * * *$ & $-0.02(0.00)^{* * *}$ & $-0.16(0.04)^{* * *}$ \\
\hline $\begin{array}{r}\text { Mothers relationship quality } \\
\text { with partner }\end{array}$ & $-0.01(0.01)$ & $-0.01(0.01)$ & $-0.19(0.08)^{*}$ \\
\hline Days a week dinner with family & $0.00(0.00)^{*}$ & $0.00(0.00)$ & $-0.09(0.02)^{* * *}$ \\
\hline Yr9 Internalizing & $0.01(0.01)$ & - & - \\
\hline Yr9 Externalizing & - & $0.00(0.00)^{*}$ & - \\
\hline Yr9 Delinquency & - & - & $0.04(0.01)^{* * *}$ \\
\hline
\end{tabular}

Note: $N=3,146$ for both models. Results combined across 20 imputed datasets. Model 4 run separately.

$+p<.10 .{ }^{*} p<0.05 . * * p<.01 * * * . p<.001$ 
Figures

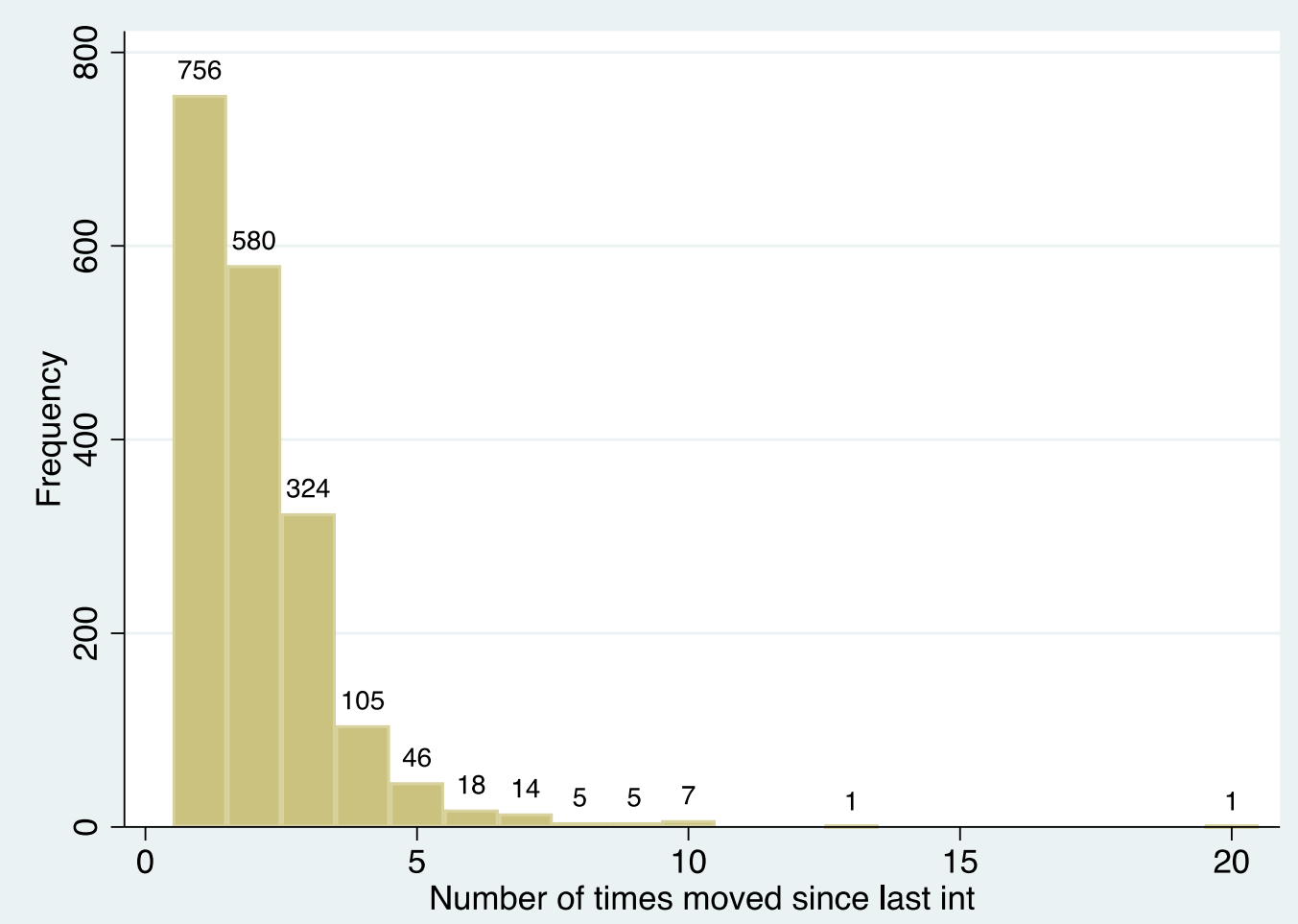

Figure 1. Histogram illustrating number of moves experienced since year 9 interview. 


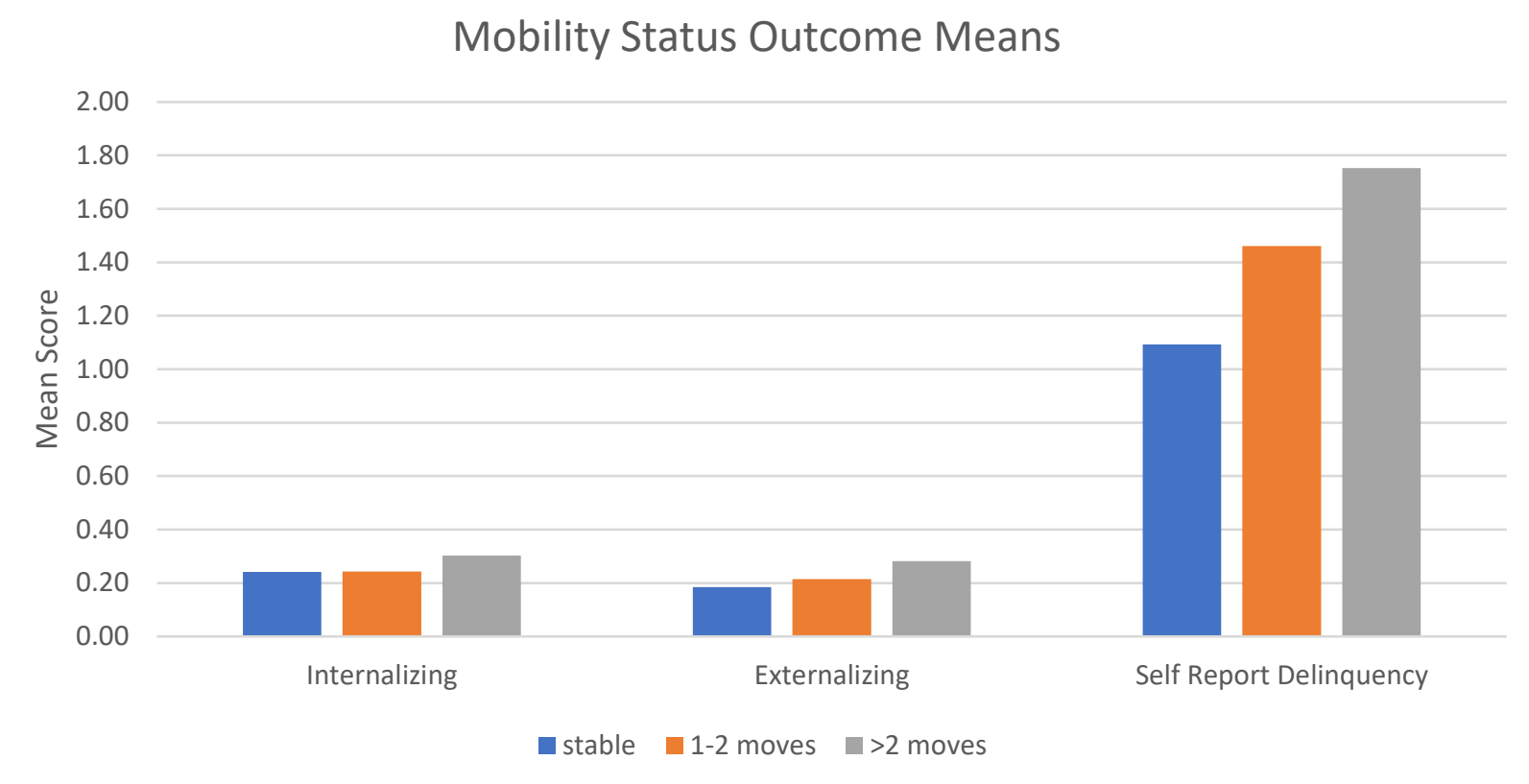

Figure 2. Mean score of each mobility group by outcome.

Note: Internalizing range: 0-4, Externalizing range: 0-4, Delinquency range: 0-27. 


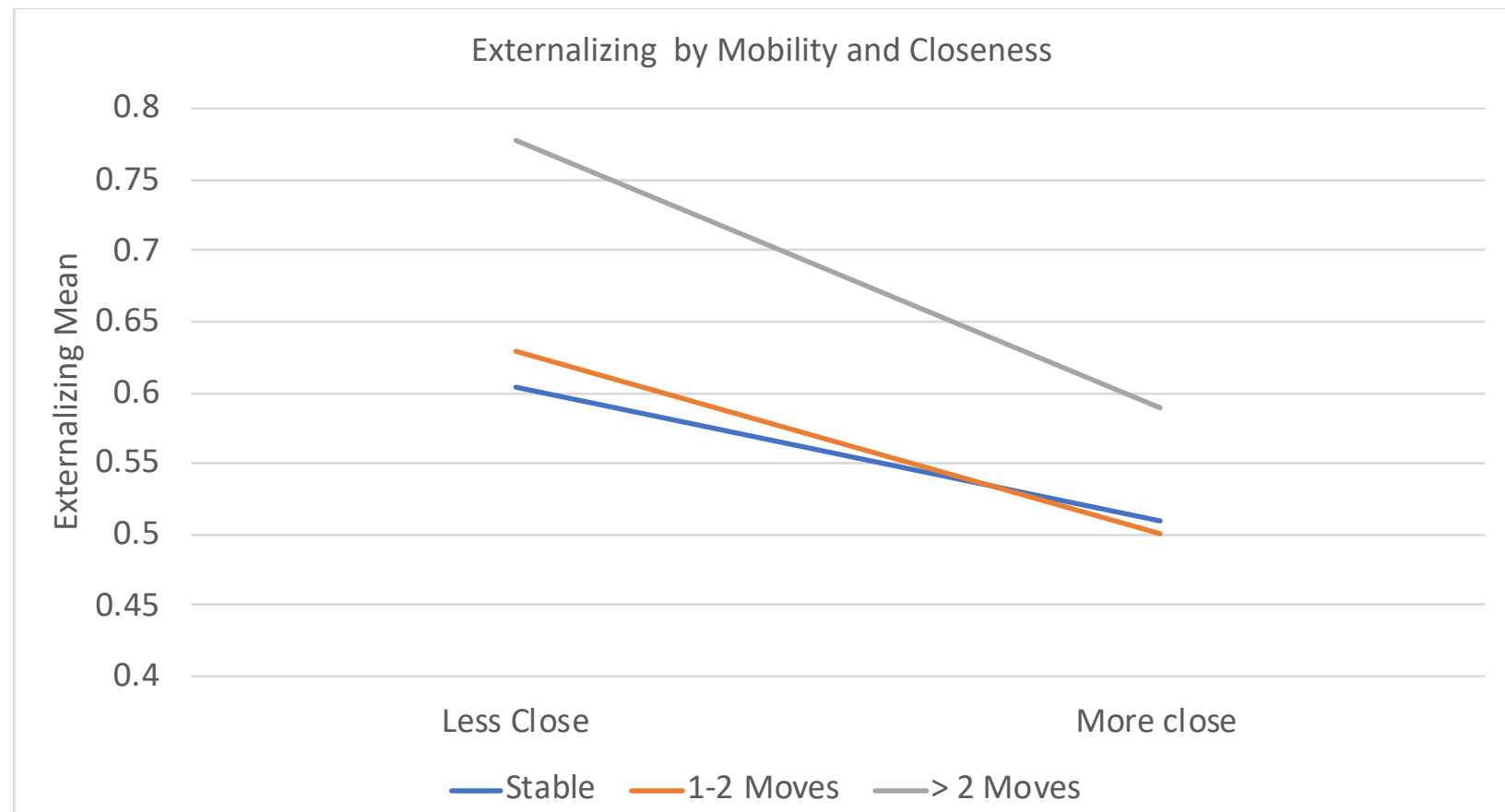

Figure 3. Interaction between mother-adolescent closeness, externalizing, and mobility Note: $p<0.05$ for low mobility group x mother-adolescent closeness $p<0.01$ for high mobility group $\mathrm{x}$ mother-adolescent closeness 
Appendix A

Section of Year 15 PCG Survey for Mobility Characteristics:

Now I would like to ask you some questions about your housing situation.

J1. Have you moved since \{MONTH AND YEAR COHORT CITY FIELDED IN YR 9\}? YES

NO 2 GO TO J6

REFUSED

-1 GO TO J6

DON'T KNOW -2 GO TO J6

J2. How many times have you moved since \{MONTH AND YEAR COHORT CITY FIELDED IN YR 9\}? *

NUMBER OF TIMES

REFUSED $-1$

DON'T KNOW $-2$ 


\section{Appendix B}

Section of Year 15 PCG Survey for PCG Reported Teen Externalizing* and Internalizing Behaviors:

*indicates statement used to calculate externalizing behavior score

The following questions are about problems and behaviors some teens show. For each behavior, please tell me whether, so far as you know, this is not true, sometimes true, or often true of $\{$ YOUTH $\}$.

PROBE: Would you say this is not true, so far as you know, sometimes true, or often true for $\{$ YOUTH $\}$.

B35. Is cruel, bullies, or shows meanness to others*

Not True, 1

Sometimes True, or 2

Often True? 3

REFUSED $-1$

DON'T KNOW $-2$

B36. Cries a lot

Not True, 1

Sometimes True, or ................................................................ 2

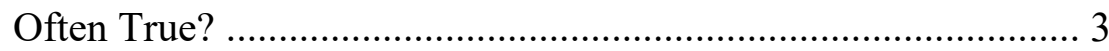

REFUSED .................................................................... -1

DON'T KNOW ............................................................. -2

B37. Destroys things belonging to the family or others*

Not True, ....................................................................... 1

Sometimes True, or ............................................................... 2

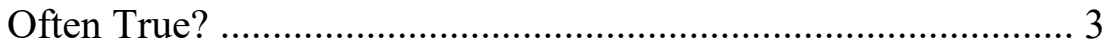

REFUSED …........................................................... -1

DON'T KNOW …….................................................. -2

B38. Is disobedient at home*

Not True, ..................................................................... 1

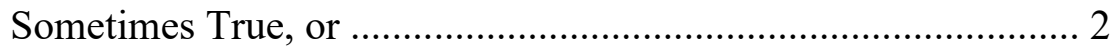

Often True? ........................................................................ 3

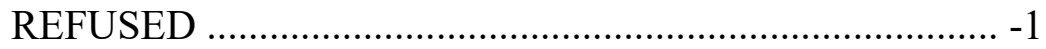

DON'T KNOW …........................................................ -2 
B39. Is disobedient at school*

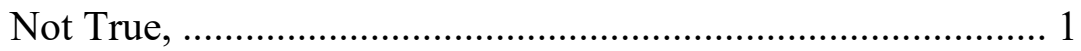

Sometimes True, or .............................................................. 2

Often True? .......................................................................... 3

REFUSED …............................................................... -1

DON'T KNOW …........................................................... -2

\section{B40. Feels worthless or inferior}

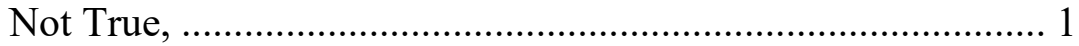

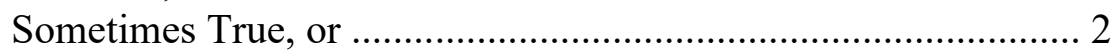

Often True? ...................................................................... 3

REFUSED ..................................................................... -1

DON'T KNOW .............................................................. -2

\section{B41. Gets in many fights*}

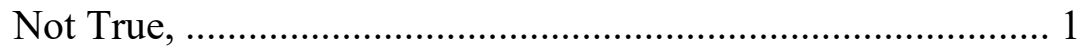

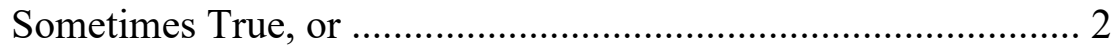

Often True? ............................................................................ 3

REFUSED …............................................................ -1

DON'T KNOW ............................................................. -2

B42. Physically attacks people*

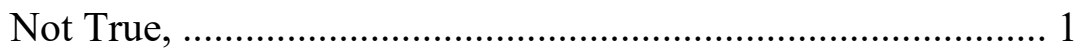

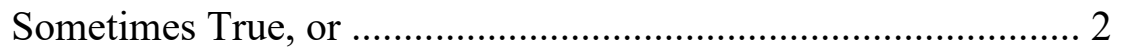

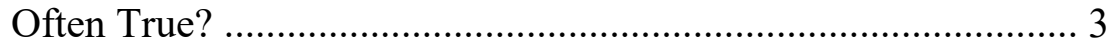

REFUSED …............................................................. -1

DON'T KNOW …........................................................... -2

B43. Is stubborn, sullen, or irritable*

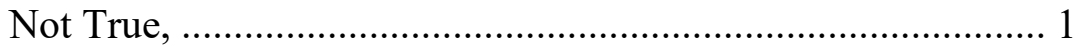

Sometimes True, or …........................................................ 2

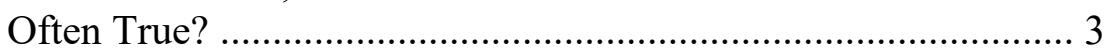

REFUSED .............................................................. -1

DON'T KNOW …............................................................ -2

B44. Has temper tantrums or a hot temper*

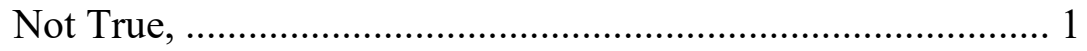

Sometimes True, or .................................................................. 2

Often True? ....................................................................... 3 
REFUSED ................................................................ -1

DON'T KNOW …............................................................. -2

\section{B45. Threatens people*}

Not True, ....................................................................... 1

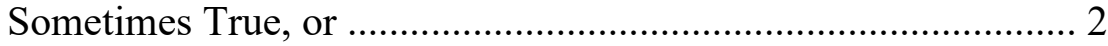

Often True? ................................................................... 3

REFUSED ..................................................................... -1

DON'T KNOW …........................................................... -2

B46. Can't concentrate, or can't pay attention for long

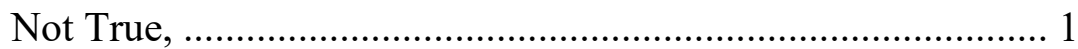

Sometimes True, or ................................................................ 2

Often True? ........................................................................... 3

REFUSED ….................................................................. -1

DON'T KNOW …....................................................... -2

B47. Can't sit still; is restless or hyperactive

Not True, ....................................................................... 1

Sometimes True, or ................................................................. 2

Often True? ......................................................................... 3

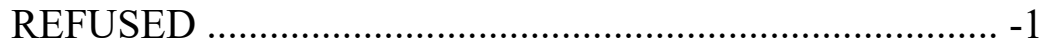

DON'T KNOW ................................................................. -2

B48. Is impulsive or acts without thinking

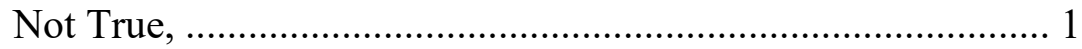

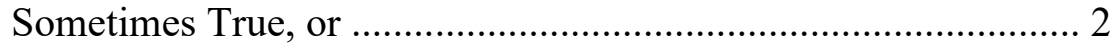

Often True? ....................................................................... 3

REFUSED …................................................................. -1

DON'T KNOW ............................................................. -2

B49. Doesn't seem to feel guilty after misbehaving*

Not True, .......................................................................... 1

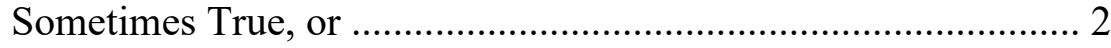

Often True? ...................................................................... 3

REFUSED …................................................................ -1

DON'T KNOW …....................................................... -2

B50. Hangs around with others who get in trouble*

Not True, 


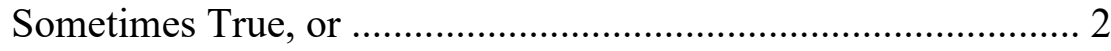

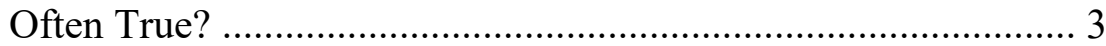

REFUSED ….................................................................. -1

DON'T KNOW ............................................................... -2

B51. Lies or cheats*

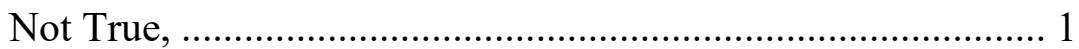

Sometimes True, or ................................................................. 2

Often True? ….................................................................. 3

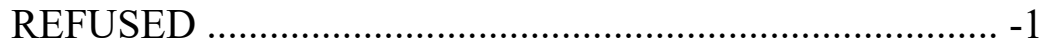

DON'T KNOW .................................................................. -2

B52. Is nervous, high strung, or tense

Not True, ...................................................................... 1

Sometimes True, or ................................................................ 2

Often True? ................................................................. 3

REFUSED …............................................................. -1

DON'T KNOW ............................................................... -2

\section{B53. Is too fearful or anxious}

Not True, .................................................................... 1

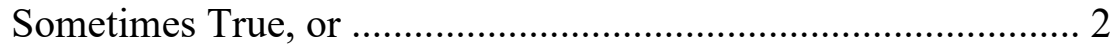

Often True? .................................................................... 3

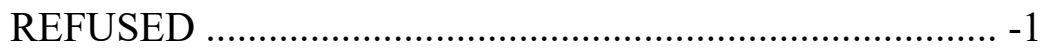

DON'T KNOW …........................................................... -2

\section{B54. Feels too guilty}

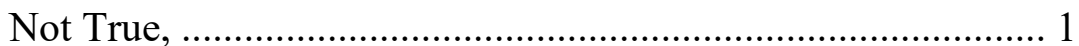

Sometimes True, or ................................................................ 2

Often True? .............................................................................. 3

REFUSED …............................................................ -1

DON'T KNOW ................................................................. -2

\section{B57. Unusually loud*}

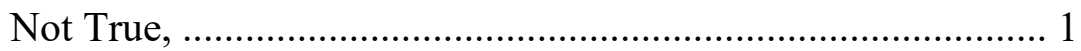

Sometimes True, or ................................................................ 2

Often True? ................................................................... 3

REFUSED ….......................................................... -1

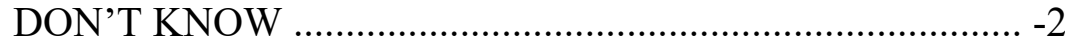

B59. Argues a lot* 
Not True, .......................................................................... 1

Sometimes True, or ............................................................... 2

Often True? ................................................................... 3

REFUSED ................................................................. -1

DON'T KNOW .............................................................. -2

B60. Runs away from home*

Not True, .............................................................................. 1

Sometimes True, or ............................................................... 2

Often True? ........................................................................ 3

REFUSED ….......................................................... -1

DON'T KNOW …......................................................... -2

B61. Sets fires*

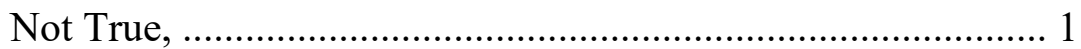

Sometimes True, or .............................................................. 2

Often True? ........................................................................... 3

REFUSED .............................................................. -1

DON'T KNOW …............................................................ -2

\section{B62. Steals at home*}

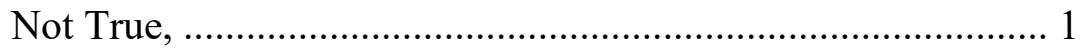

Sometimes True, or ................................................................ 2

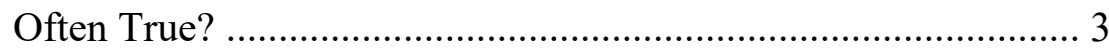

REFUSED .............................................................. -1

DON'T KNOW ............................................................. -2

\section{B63. Steals outside the home*}

Not True, ........................................................................ 1

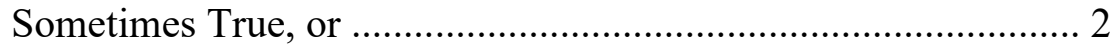

Often True? ....................................................................... 3

REFUSED ……...................................................... -1

DON'T KNOW …….................................................. -2

B64. Swears or uses obscene language*

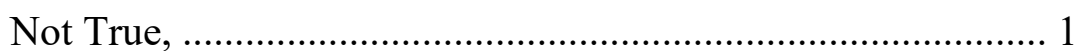

Sometimes True, or ............................................................. 2

Often True? ........................................................................ 3

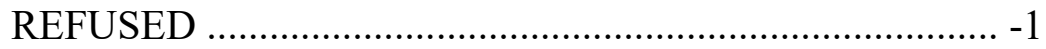

DON'T KNOW …........................................................ -2 
B65. Is underactive, slow moving, or lacks energy

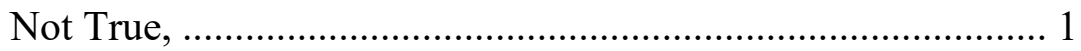

Sometimes True, or ................................................................ 2

Often True? .................................................................... 3

REFUSED …............................................................... -1

DON'T KNOW ............................................................. -2

B66. Is unhappy, sad or depressed

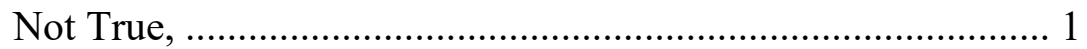

Sometimes True, or ............................................................... 2

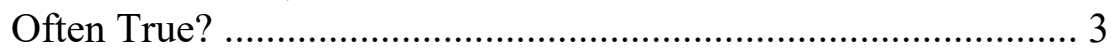

REFUSED ..................................................................... -1

DON'T KNOW .............................................................. -2

B67. Vandalizes*

Not True, .......................................................................... 1

Sometimes True, or ............................................................... 2

Often True? ....................................................................... 3

REFUSED …............................................................ -1

DON'T KNOW …....................................................... -2

B68. Worries

Not True, .......................................................................... 1

Sometimes True, or ................................................................ 2

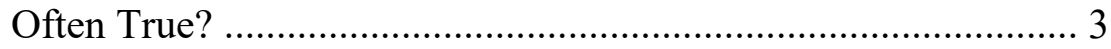

REFUSED ….............................................................. -1

DON'T KNOW ….......................................................... -2 


\section{Appendix C}

Section of Year 15 Youth Survey for Teen Reported Delinquent Behaviors:

D61. The next few questions are about vandalism and violence.

For each item I read, tell me how often in the past 12 months you did these things. Tell me whether you never did it or did it 1 or 2 times, 3 or 4 times, or 5 or more times.

PROBE: Would you say never, 1 or 2 times, 3 or 4 times, 5 or more times in the past 12 months?

D61A. Paint graffiti or signs on someone else's property or in a public place?

Never, 1

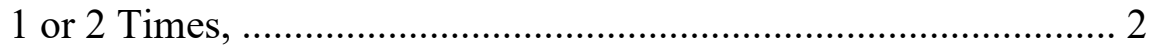

3 or 4 Times, or ...................................................................... 3

5 or More Times? ......................................................................... 4

REFUSED …............................................................. -1

DON'T KNOW ............................................................... -2

D61B. Deliberately damage property that didn't belong to you?

Never, 1

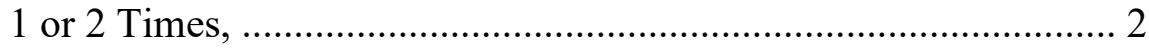

3 or 4 Times, or ........................................................................... 3

5 or More Times? ......................................................................... 4

REFUSED …............................................................. -1

DON'T KNOW …........................................................... -2

D61C. Take something from a store without paying for it?

Never, 1

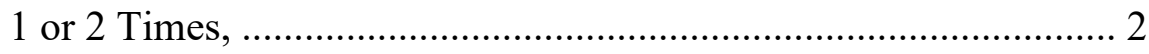

3 or 4 Times, or ............................................................................ 3

5 or More Times? ............................................................................... 4

REFUSED …............................................................ -1

DON'T KNOW …….................................................. -2

D61D. Get into a serious physical fight?

Never, 1

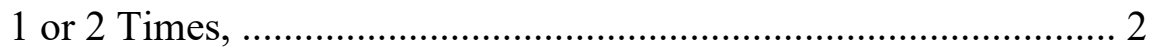

3 or 4 Times, or n.................................................................... 3

5 or More Times? ............................................................................... 4

REFUSED …........................................................ -1 
DON'T KNOW $-2$

D61E. Hurt someone badly enough to need bandages or care from a doctor or nurse?

Never, 1

1 or 2 Times, 2

3 or 4 Times, or 3

5 or More Times? 4

REFUSED $-1$

DON'T KNOW $-2$

D61F. Drive a car without its owner's permission?

Never, 1

1 or 2 Times, 2

3 or 4 Times, or 3

5 or More Times? 4

REFUSED $-1$

DON'T KNOW $-2$

D61G. Steal something worth more than $\$ 50$ ?

Never, 1

1 or 2 Times, 2

3 or 4 Times, or 3

5 or More Times?

REFUSED $-1$

DON'T KNOW $-2$

D61H. Go into a house or building to steal something?

Never, 1

1 or 2 Times, 2

3 or 4 Times, or 3

5 or More Times?

REFUSED 4

DON'T KNOW $-1$

D61I. Use or threaten to use a weapon to get something from someone?

Never, 1

1 or 2 Times, 2

3 or 4 Times, or 3

5 or More Times? 4

REFUSED $-1$

DON'T KNOW $-2$ 
D61J. Sell marijuana or other drugs?

Never, ....................................................................... 1

1 or 2 Times, ................................................................ 2

3 or 4 Times, or ….................................................................... 3

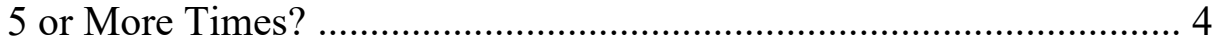

REFUSED …............................................................

DON'T KNOW …......................................................... -2

D61K. Steal something worth less than $\$ 50 ?$

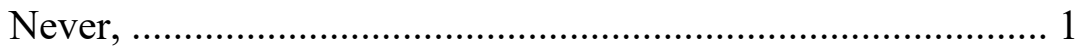

1 or 2 Times, ..................................................................... 2

3 or 4 Times, or ................................................................... 3

5 or More Times? ............................................................................... 4

REFUSED ..................................................................... -1

DON'T KNOW …........................................................ -2

D61L.Take part in a fight where a group of your friends was against another group?

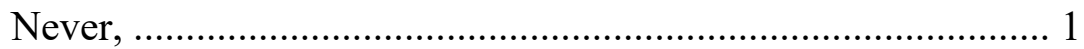

1 or 2 Times, ........................................................................ 2

3 or 4 Times, or …..................................................................... 3

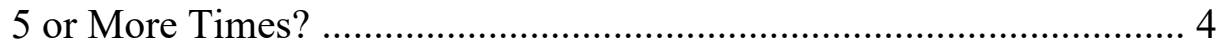

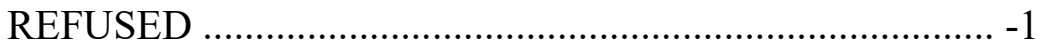

DON'T KNOW ............................................................ -2

D61M. Were you loud, rowdy, or unruly in a public place?

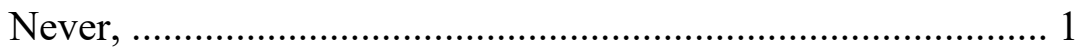

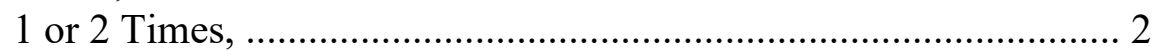

3 or 4 Times, or .................................................................... 3

5 or More Times? .............................................................................. 4

REFUSED …............................................................ -1

DON'T KNOW ............................................................ -2 


\section{Appendix D}

\section{Section of Year 15 PCG Survey for Parental Monitoring:}

C7. I am going to name some things parents often set limits about. Tell me who decides if $\{$ YOUTH can do these things. Do you decide, does $\{$ YOUTH\} decide, or do you and $\{$ YOUTH $\}$ jointly decide if $\{$ YOUTH $\}$ can do these things?

PROBE: Do you decide, does $\{$ YOUTH $\}$ decide, or do you and $\{$ YOUTH $\}$ jointly decide?

C7A. How late \{YOUTH\} stays out at night?

Respondent Decides 1

Youth Decides, or 2

Respondent and Youth Jointly Decide? 3

REFUSED $-1$

DON'T KNOW $-2$

C7B. What kinds of TV shows and movies \{YOUTH\} watches?

Respondent Decides, Youth Decides, or 2

Respondent and Youth Jointly Decide? 3

REFUSED $-1$

DON'T KNOW $-2$

C7C. Who \{YOUTH $\}$ can hang out with?

Respondent Decides, 1

Youth Decides, or 2

Respondent and Youth Jointly Decide?

REFUSED $-1$

DON'T KNOW $-2$

D21a. How many of \{YOUTH\}'s close friends do you know by first and last name?

TEEN HAS FRIENDS 1

TEEN HAS NO FRIENDS 2 GO TO D24

IF PCG PROVIDES A NUMBER, CODE 1 FOR TEEN HAS FRIENDS. ELSE IF PCG OFFERS THAT TEEN HAS NO FRIENDS, CODE 2 FOR TEEN HAS NO FRIENDS.

IF DON'T KNOW OR REFUSED, CODE AS “1-TEEN HAS FRIENDS” AND CODE AS DON'T KNOW OR REFUSED ON THE NEXT SCREEN.

Section of Year 15 Youth Survey for Parental Monitoring: 
C7. I am going to name some things parents often set limits about. Thinking only about the parents or guardians in your house, tell me who decides if you can do these things. Do your parents or guardians decide, do you decide, or do you and your parents or guardians jointly decide if you can do these things?

PROBE: Do your parents or guardians decide, do you decide, or do you and your parents or guardians jointly decide?

C7A. How late you can stay out at night?

Parents/Guardians Decide, 1

Youth Decides for Himself or Herself, or 2

Parents/Guardians and Youth Jointly Decide?

REFUSED $-1$

DON'T KNOW $-2$

C7B. What kinds of TV shows and movies you can watch?

Parents/Guardians Decide, 1

Youth Decides for Himself or Herself, or 2

Parents/Guardians and Youth Jointly Decide? 3

REFUSED $-1$

DON'T KNOW $-2$

C7C. Who you can hang out with?

Parents/Guardians Decide, 1

Youth Decides for Himself or Herself, or 2

Parents/Guardians and Youth Jointly Decide? 3

REFUSED $-1$

DON'T KNOW $-2$ 


\section{Appendix E}

\section{Question from Year 15 PCG Survey for PCG Reported Closeness to Youth:}

D37. How close do you feel to $\{$ YOUTH $\}$ ? Would you say...

Extremely close, ....................................................... 1

Quite close, ........................................................... 2

Fairly close, or ........................................................... 3

Not very close? ...................................................... 4

REFUSED …............................................................ -1

DON'T KNOW ....................................................... -2

Section of Year 15 Youth Survey for Teen Reported Closeness to Biological Mother:

C17. How close do you feel to your mom? Would you say...

Extremely close, ......................................................... 1

Quite close, ............................................................. 2

Fairly close, or ........................................................... 3

Not very close? ........................................................... 4

REFUSED ............................................................ -1

DON'T KNOW ….......................................................... -2

If YOUTH HAS NOT SEEN BIOMOTHER IN PAST YEAR (C10=2, -1, -2) AND YOUTH HAS NOT COMMUNICATED WITH BIOMOTHER IN PAST YEAR $(\mathrm{C} 11=2,-1,-2)$, GO TO BOX C19.

ELSE, GO TO C18.

C18. How well do you and your mom share ideas or talk about things that really matter? Would you say...

Extremely well, ....................................................... 1

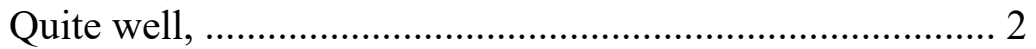

Fairly well, or ............................................................. 3

Not very well? ........................................................... 4

REFUSED .............................................................. -1

DON'T KNOW …........................................................... -2

If BIOMOTHER $=$ PCG $(C O N F 1 D=1)$ OR YOUTH SAW MOTHER $(C 12>0)$ OR COMMUNICATED WITH MOTHER (C13 >0) IN LAST 30 DAYS, GO TO C19A. ELSE, GO TO BOX C20.

Section of Year 15 Youth Survey for Teen Reported Closeness to Biological Father:

C28. How close do you feel to your dad? Would you say... 
Extremely close, ........................................................ 1

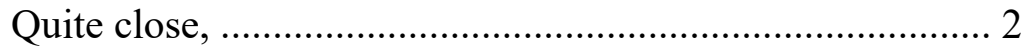

Fairly close, or .............................................................. 3

Not very close? ........................................................ 4

REFUSED ............................................................. -1

DON'T KNOW .............................................................. -2

IF YOUTH HAS NOT SEEN BIOFATHER IN PAST YEAR (C21=2, -1, -2) AND YOUTH HAS NOT COMMUNICATED WITH BIOFATHER IN PAST YEAR (C22=2, -1, -2), GO TO BOX C30. ELSE, GO TO C29.

C29. How well do you and your dad share ideas or talk about things that really matter? Would you say...

Extremely well, .......................................................... 1

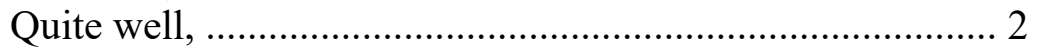

Fairly well, or ............................................................. 3

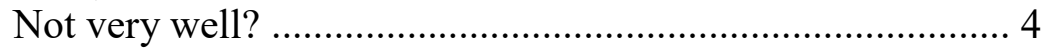

REFUSED ................................................................. -1

DON'T KNOW ............................................................ -2

If BIOFATHER $=$ PCG $($ CONF1D $=2)$ or TEEN LIVES WITH BIOFATHER $($ CONF2 $=1)$ OR TEEN SAW FATHER $($ C23 > 0) OR COMMUNICATED WITH FATHER (C24 >0) IN LAST 30 DAYS, GO TO C30.

ELSE, GO TO BOX C31. 


\section{Appendix F}

Section of Year 15 PCG Survey for Measuring PCG Depression in the Past 6 Months:

H7. During the past twelve months, has there ever been a time when you felt sad, blue, or depressed for two or more weeks in a row?
YES 1
$\mathrm{NO}$ 2 GO TO H11
NO, ON MEDICATION/ANTI-DEPRESSANTS (VOLUNTEERED) 14 GO TO H11
REFUSED -1 GO TO H11
DON'T KNOW -2 GO TO H11

For the next two questions, please think of the two-week period during the past twelve months when these feelings were worst.

H8. During that time, did the feelings of being sad, blue, or depressed usually last ...

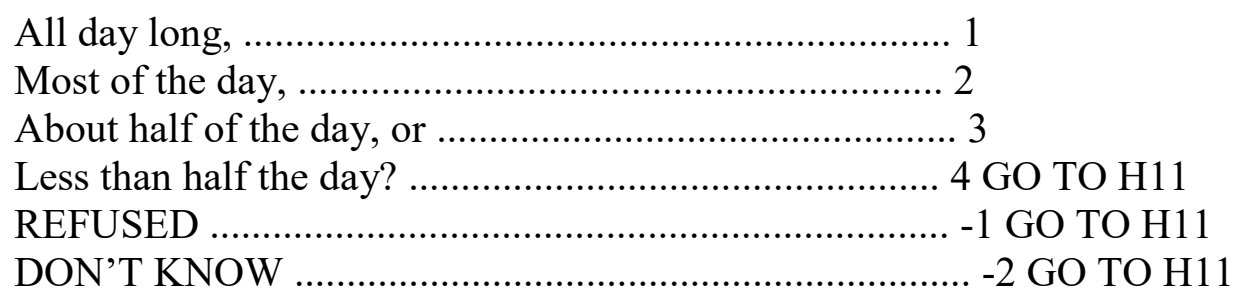

H9. During those two weeks, did you feel this way ...

Every day, 1

Almost every day, or ............................................... 2

Less often? ............................................................... 3 GO TO H11

REFUSED ….................................................... -1 GO TO H1 1

DON'T KNOW ......................................................... - 2 GO TO H11

H10. During those two weeks did you lose interest in most things like hobbies, work, or activities that usually give you pleasure?

YES …............................................................... 1

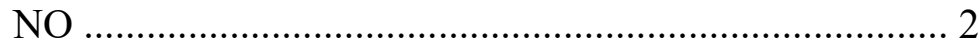

REFUSED …....................................................... -1

DON'T KNOW …........................................................ -2

H14. Thinking about those same two weeks, did you feel more tired out or low on energy than is usual for you?

YES 1 
NO …............................................................... 2

REFUSED …........................................................ -1

DON'T KNOW .............................................................. -2

H15. During these two weeks, did you gain or lose weight without trying, or did you stay about the same?

PROBE: We are still talking about the same two weeks.

GAIN 1

LOSE 2

IF VOLUNTEERED: BOTH GAINED AND LOST WEIGHT 3

STAYED ABOUT THE SAME 4 GO TO H17

IF VOLUNTEERED: WAS ON A DIET 5 GO TO H17

REFUSED -1 GO TO H17

DON'T KNOW -2 GO TO H17

H17. Did you have more trouble falling asleep than you usually do during those two weeks?
YES 1
NO . 2 GO TO H19
REFUSED -1 GO TO H19
DON'T KNOW -2 GO TO H19

H18. Did that happen every night, nearly every night, or less often during those two weeks?

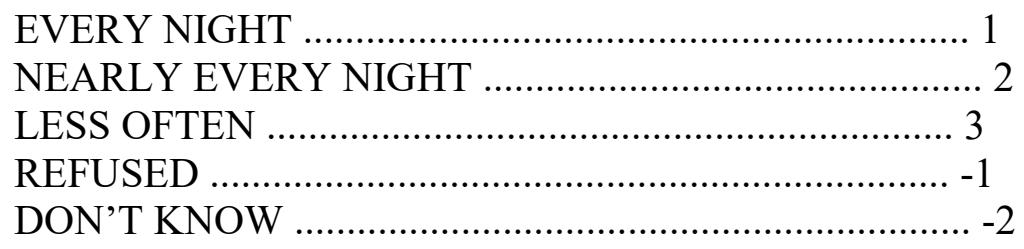

H19. During those two weeks, did you have a lot more trouble concentrating than usual?

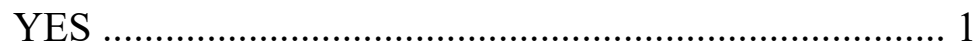

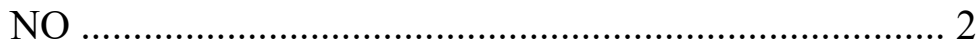

REFUSED …........................................................ -1

DON'T KNOW ........................................................... -2

H20. People sometimes feel down on themselves, no good, or worthless. During that two week period, did you feel this way?

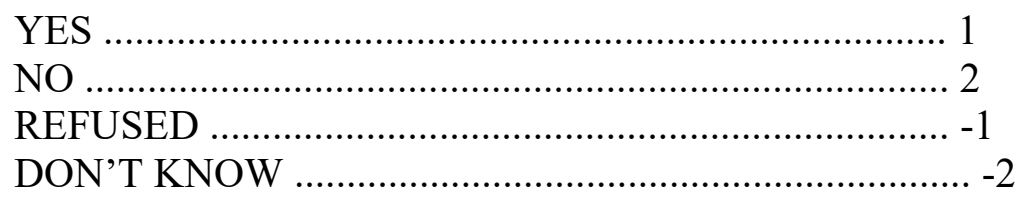


H21. Did you think a lot about death--either your own, someone else's, or death in general during those two weeks?

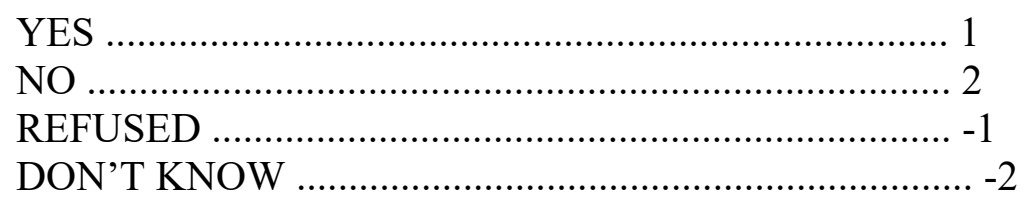




\section{Appendix G}

\section{Section of Year 15 PCG Survey Used to Collect Income Information:}

K57. In the past twelve months, what was the total income of your household from all sources before taxes and other deductions? Please include your own income and the income of everyone living with you. Please include the money you have told me about from jobs and public assistance programs, as well as any sources we haven't discussed, such as rent, interest, and dividends.

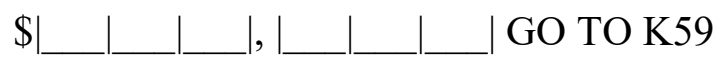

ENTER AMOUNT

REFUSED $-1$

DON'T KNOW $-2$

SOFT RANGE: $\$ 500-\$ 90,000$

HARD RANGE \$1-\$999, 999

K58. I just need to have a range. Can you tell me if it was ...?

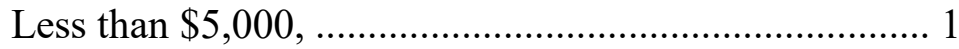

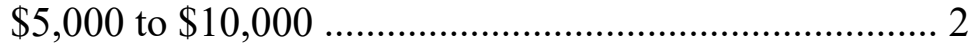

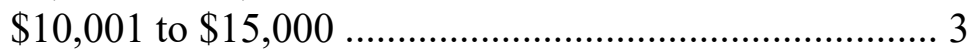

$\$ 15,001$ to $\$ 20,000$................................................... 4

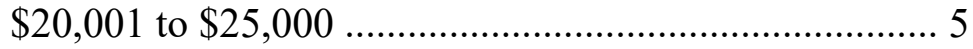

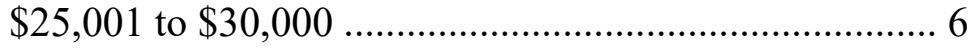

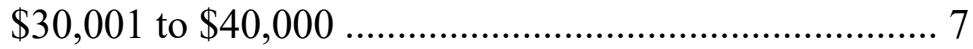

$\$ 40,001$ to $\$ 60,000$, or ................................................. 8

More than $\$ 60,000$ ? ................................................... 9

REFUSED ........................................................... -1

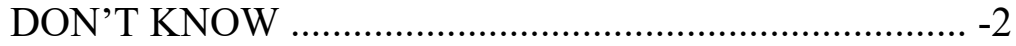




\section{Appendix H}

Section of Year 15 Youth Survey for Teen Reported Race/Ethnicity:

The next set of questions is about you, your family and home.

COOA. What is your race and ethnicity?

ENTER RESPONSE:

REFUSED …........................................................... -1

DON'T KNOW ….......................................................... -2

RANGE: 0 -80 characters

RECODED (C00aa-C00as)

C00aa. Youth specified White or Caucasian Yes/No

C00ab. Youth specified Black or African American Yes/No

C00ac. Youth specified American Indian or Alaska Native Yes/No

C00ad. Youth specified Asian or with an Asian nationality or ethnic group Yes/No

C00ae. Youth specified Native Hawaiian or Pacific Islander or with a relevant nationality

Yes/No

C00af. Youth specified Hispanic/Latino or with a relevant nationality Yes/No

C00ag. Youth specified European nationality Yes/No

$\mathrm{C} 00 \mathrm{ah}$. Youth specified Central American or Caribbean nationality Yes/No

C00ai. Youth specified Mexican nationality Yes/No

C00aj. Youth specified South American nationality Yes/No

C00ak. Youth used term 'mixed,' 'multi-racial,' or 'bi-racial' Yes/No

C00al. Youth specified American only Yes/No

C00am. Youth specified a religious category" Yes/No

C00an. Youth specified other or unspecified race/ethnicity Yes/No 


\section{Appendix I}

Section of Year 15 PCG Survey for PCG relationships:

\section{CONFIRM THE FOLLOWING FROM THE INTRO SCRIPT. CODE WITHOUT ASKING IF KNOWN}

\section{CONF1: WHAT IS THE RESPONDENT'S RELATIONSHIP TO \{YOUTH FIRST AND} LAST NAME\}?

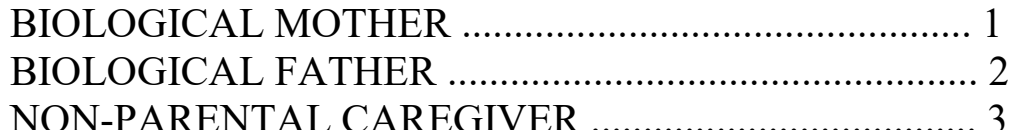

E1. What is your relationship with $\{$ YOUTH\}'s biological $\{$ father, $\{$ BIOFATHER $\} /$ mother, \{BIOMOTHER\}\} now? Are you...

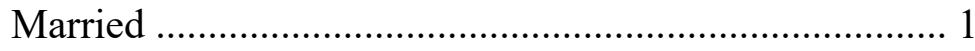

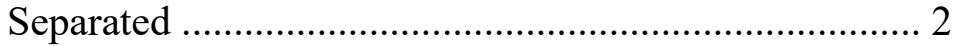

Divorced .................................................................. 3

Cohabiting, or living together .................................... 4

Romantically involved, but living apart....................... 5

Just friends or ..................................................... 6

Not in any kind of relationship? .................................. 7

\{BIOFATHER/BIOMOTHER $\}$ DECEASED,

VOLUNTEERED .................................................... 8

\{BIOFATHER NOT KNOWN …................................. 9

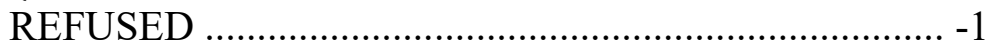

DON'T KNOW .......................................................... -2

E8. Are you currently involved in a romantic relationship with someone \{other than \{BIOFATHER/BIOMOTHER\}\}?

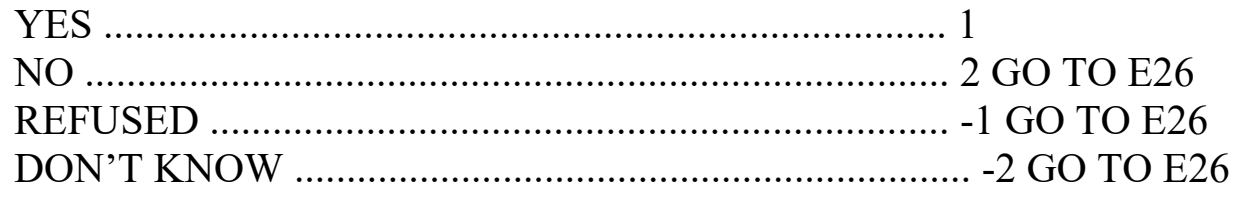

E10. How do you describe your romantic relationship with \{CURRENT PARTNER\}?

Married

1 GO TO E11A

Cohabiting or living together ...................................... 2 GO TO E12A

Romantically involved and living apart........................ 3 GO TO E13

REFUSED

-1 GO TO E13

DON'T KNOW

-2 GO TO E13 
Section of Year 15 OCG Survey for Current Education Level:

K3A. What is the highest grade of school you have completed, or the highest degree you have received?

NONE $1 \mathrm{GO}$ TO K4

ELEMENTARY, MIDDLE, OR

JUNIOR HIGH SCHOOL 2

SOME REGULAR HIGH SCHOOL ............................... 3

HIGH SCHOOL DIPLOMA ....................................... 4

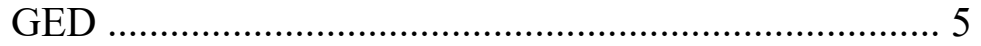

ABE PROGRAM …..................................................... 6

NURSING SCHOOL (LPN OR RN) …........................ 7

BUSINESS OR SECRETARIAL SCHOOL .................... 8

VOCATIONAL, TECHNICAL, OR TRADE SCHOOL ..... 9

JUNIOR/COMMUNITY COLLEGE (2-YEAR) ................. 10

SOME COLLEGE ….............................................. 11

COLLEGE (4-YEAR) DEGREE ……........................... 12

GRADUATE OR PROFESSIONAL SCHOOL ............... 13

OTHER TYPE OF SCHOOL ....................................... 14

REFUSED ............................................................. -1

DON'T KNOW ….................................................... -2

Section of Year 15 Youth Survey for Relationship Quality Between Parents and Parents'

Partners:

IF PRELOAD INDICATES EITHER BIOMOTHER IS DECEASED (MOMSTAT=90) OR CONF9A $=1$ OR CONF6A=1OR BIOFATHER IS DECEASED OR CONF10=1 OR CONF2A $=1$ OR FATHER DENIES/NOT TOLD OF PATERNITY, DNA PROVES NOT FATHER, OR FATHER UNKNOWN FROM YR9 FATHER INTERVIEW STATUS $($ DADSTAT $=90,92,93,94)$, GO TO BOX C2 ELSE IF PCG = NONPARENT (CONF1D=3), GO TO C3.

ELSE GO TO C1.

C1. First, I'd like to ask you about the relationship between your biological parents. In general, would you say that your \{mother's/father's\} relationship with your \{father/mother $\}$ is excellent, very good, good, fair, or poor?

EXCELLENT …......................................................... 1

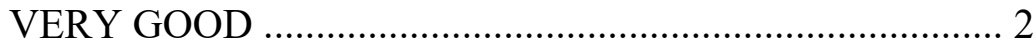

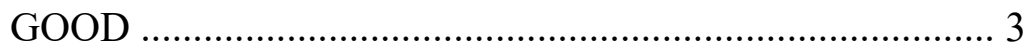

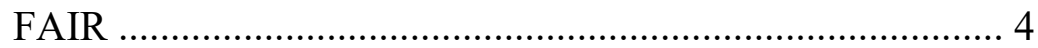

POOR ................................................................... 5

REFUSED …........................................................... -1

DON'T KNOW ............................................................ -2 
PROGRAMMER INSTRUCTIONS: If CONF1D=1, display “mother's" and "father." If CONF1D=2, display "father's" and "mother."

IF THE YOUTH'S PRIMARY CAREGIVER IS HIS/HER BIOMOTHER (CONF1D=1) AND IF BIOMOTHER HAS A CURRENT PARTNER THAT IS NOT THE BIOFATHER (CONF3=1); OR IF THE YOUTH'S PRIMARY CAREGIVER IS HIS/HER BIOFATHER $(C O N F 1 D=2)$ AND IF BIOFATHER HAS A CURRENT PARTNER THAT IS NOT THE BIOMOTHER (CONF7=1), THEN GO TO C2.

ELSE, GO TO C3.

C2. In general, would you say that your \{mother's/father's $\}$ relationship with $\{$ PARTNER\} is excellent, very good, good, fair, or poor?

EXCELLENT ............................................................... 1

VERY GOOD …......................................................... 2

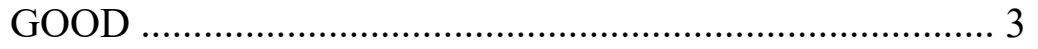

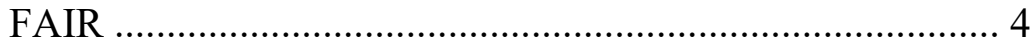

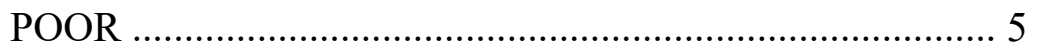

REFUSED ................................................................. -1

DON'T KNOW ........................................................ -2

PROGRAMMER INSTRUCTIONS: If CONF1D=1 (PCG IS MOM), display “mother's." If CONF1D=2 (PCG IS DAD), display "father's." 


\section{Appendix J}

\section{Section of Year 9 Youth Survey for Teen Reported Delinquent Behavior:}

Focal teen responded yes or no to having committed the following statements concerning delinquent behavior:

1. Purposely damaged or destroyed property that wasn't yours

2. Taken or stolen something from another person or from a store

3. Taken money at home, like from your mother's purse/ dresser

4. Cheated on a school test

5. Had a fist fight with another person

6. Hurt an animal on purpose

7. Trespassed into somebody's garden, backyard, house, or garage

8. Ran away from home

9. Skipped school without an excuse

10. Secretly taken a sip of wine, beer, or liquor

11. Smoked marijuana, grass, pot, weed

12. Smoked a cigarette or used tobacco

13. Been suspended or expelled from school

14. Written things or spray painted on walls or sidewalks or cars

15. Purposely set fire to a building, a car, or other property or tried to do so

16. Avoided paying for movies, bus or subway rides or food

17. Thrown rocks or bottles at people or cars 